\title{
Atopic Dermatitis and Fungi
}

\author{
Jan Faergemann* \\ Department of Dermatology, Sahlgrenska University Hospital, Gothenburg, Sweden
}

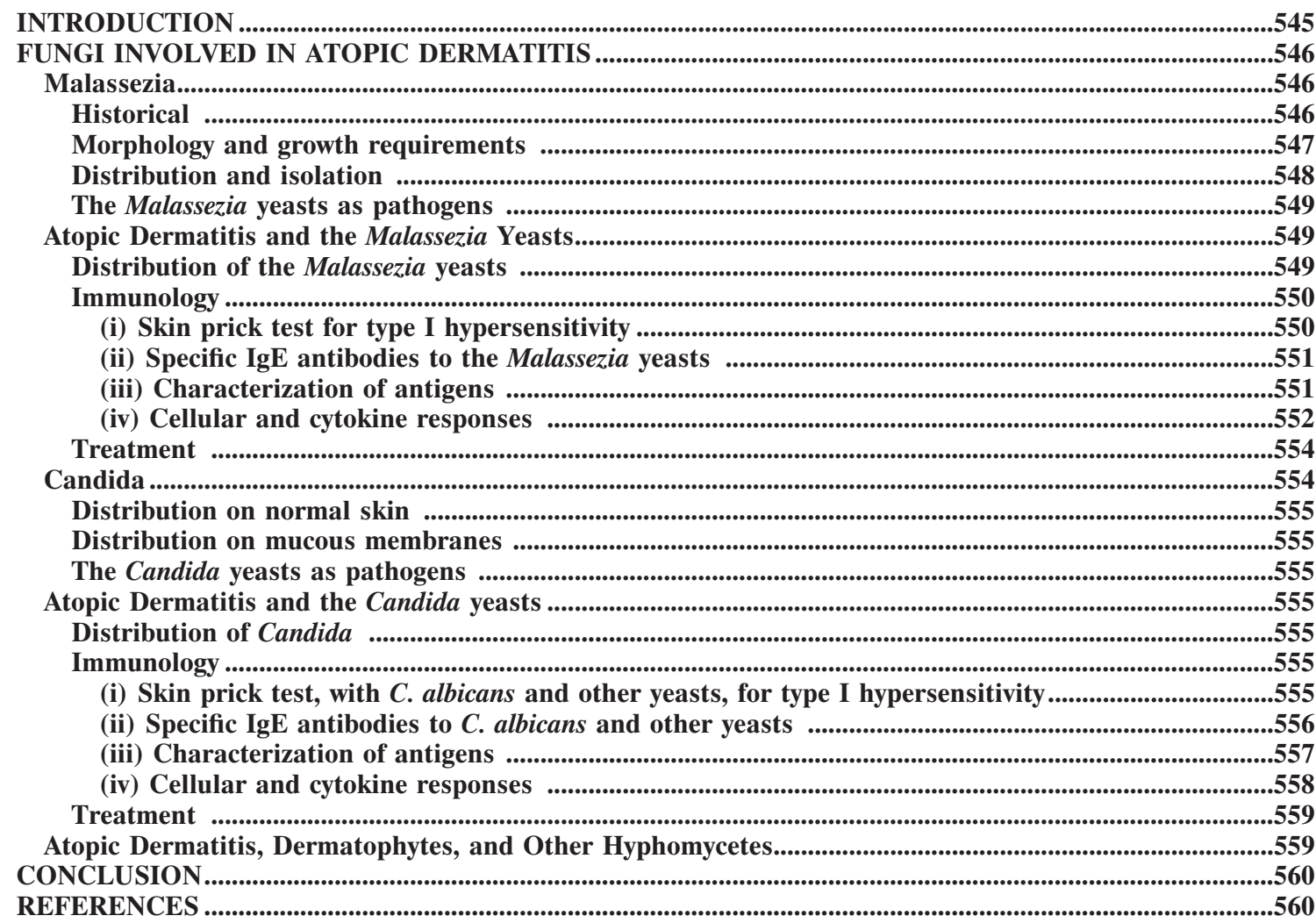

\section{INTRODUCTION}

Atopic dermatitis (AD) is a chronic, itching, inflammatory skin disease which is associated with asthma and/or hay fever and a familial occurrence of these conditions $(53,159)$. AD is the most common chronic skin disease in children $(145,160$, 161). Approximately $18 \%$ of 7 -year-old children have or have had $\mathrm{AD}$. In $90 \%$ of patients the disease starts before 7 years of age, and usually it starts before 1 year of age. The majority of the patients improve before or around puberty, and it is estimated that approximately $2 \%$ of the adult population has AD $(160,161)$. However, AD may start in adult life, although this is rare. There is a documented increase in the incidence of AD in all countries with an Western life-style, but the exact reason for this is unclear (the frequency of $\mathrm{AD}$ in 7-year-old children is 2 to $3 \%$ for those born before 1960, 4 to $8 \%$ for those born between 1960 and 1970, 9 to $12 \%$ for those born between 1970 and 1980, and 15 to $20 \%$ for those born after 1980) (152).

Genetic factors are important in the development of $\mathrm{AD}$,

* Mailing address: Department of Dermatology, Sahlgrenska University Hospital, S-413 45 Gothenburg, Sweden. Phone: 46313421000. Fax: 4631 821871. E-mail: jan.faergemann@derm.gu.se. but the exact hereditary pathway is still unknown (26a, 27, 161, 164). If both parents have had $\mathrm{AD}$, the risk for the children is approximately $70 \%$. Infiltrates of activated T-helper cells are found in the skin of patients with AD (92). There is an imbalance between Th1 and Th2 cells toward an increase in cells of the Th2 type. Th2 cells have a cytokine profile with an increased production of interleukin 4 (IL-4), which stimulates the plasma cells to an increased production of immunoglobulin $\mathrm{E}(\mathrm{IgE})(8)$. Another interesting observation in the skin of AD patients is the presence of a dendritic epidermal cell population (Langerhans' cells and mast cells) that carry IgE receptors and specific $\operatorname{IgE}(22,80,92)$. Antigen presented by these cells may stimulate Th2 cells to synthesize IgE and hence contribute to the inflammatory changes in the skin $(22,80,92)$.

When the skin of patients with $\mathrm{AD}$ is examined, it is often drier than the skin of an individual without AD $(146,164)$. It also reacts differently in response to stimulation. The white dermography appears when the skin is lightly scratched and is characterized by blood vessel constriction instead of dilation (72). The threshold for itch is also lower than in healthy individuals. Dry skin and the weakened barrier function in patients with $\mathrm{AD}$ are very important in the reactions of the patients to irritants and other external trigger factors including microor- 
ganisms $(72,146,152)$. The pathophysiology and etiology of $\mathrm{AD}$ have been reviewed and discussed in a supplement of the American Journal of Dermatology (54).

Staphylococcus aureus can be cultured from both involved and uninvolved skin in 85 to $90 \%$ of patients with $\operatorname{AD}(1,21$, $40,44,95,110)$. S. aureus may aggravate AD due to a secondary infection $(3,84,93,94,118)$. However, of greater importance is probably the presence of exotoxins and other substances from $S$. aureus that may act as allergens or, more importantly, as superantigens $(59,60,89,90,139,142,168)$. Viral infections, especially with herpes simplex virus, may also aggravate AD (84).

The yeasts Malassezia and Candida may aggravate AD due to an allergic reaction $(18,40,41,135)$. In particular, the role of the Malassezia yeasts is now documented in several papers $(18,40,41)$. Malassezia species are members of the normal human cutaneous flora, and a defect in the skin barrier may facilitate the contact of these yeasts with the immune system (41). Candida yeasts are members of the normal flora of mucous membranes, and the major contact with the immune system is through the gastrointestinal tract and, in women, even through the vagina $(111,135)$. Chronic dermatophyte infections are more common in patients with $\mathrm{AD}$, and dermatophytes, especially Trichophyton rubrum, may act as allergens $(79,139)$. The role of other hyphomycetes in AD has not been studied in detail (79).

Other important factors are food, house dust mites, topically applied irritants, psychological factors, and climate (130).

The diagnosis of $\mathrm{AD}$ is usually based on many variables, including history and clinical and laboratory findings. Rajka was the first to make a diagnostic list consisting of major and minor criteria (116). These criteria were later revised and are known as the Hanifin and Rajka criteria (53). These criteria have been scientifically evaluated and found to work fairly well in the clinical situation even though many of the criteria have no precise definition, some are nonspecific, and some are uncommon. However, Williams et al. developed a minimum list of reliable criteria for the diagnosis of $\mathrm{AD}$ that could be used in clinical as well as in epidemiological studies. The obligatory criteria are an itching skin condition or report from parents that a young child itches or scratches as if itching. Thereafter, at least three of the following criteria should be fulfilled: history of involvement of the skin folds on the flexor sides of the elbows and knees, anteriorly on the ankles, on the throat, and on the cheeks in children younger than 10 years; history of asthma or hay fever in the patient or of atopic disease in the immediate family of children younger than 4 years; history of general skin dryness during the last year; visible eczema present on the flexor sides of the elbows and knees, anteriorly on the ankles, and on the throat (or cheeks, forehead, and extensor side of the extremities in children younger than 4 years); and onset before the age of 2 years (this criterion should not be used if the child is younger than 4 years) (159).

The clinical picture varies with age and may be described in 3 different phases: infant phase (younger than 2 years), childhood phase (2 to 12 years), and adolescent/adult phase (27). Important differential diagnoses are seborrheic dermatitis, psoriasis, rosacea and perioral dermatitis, fungal infections, ichtyosis vulgaris, scabies and contact dermatitis. Accurate assessment of the extent and severity of $\mathrm{AD}$ is essential for quantitating the baseline clinical disease burden and the effectiveness of treatment regimens being tested (56). One assessment system that is videly used is the SCORAD method (141), and another method is the EASI (56). It is beyond the scope of this article to discuss which one may be superior.

Treatment of AD is topical with emollients, corticosteroids, or immunomodulating agents $(17,40,55,91)$. The use of topical tacrolimus is a new approach to the treatment of $\mathrm{AD}(55)$. In severe $\mathrm{AD}$, systemic treatment with corticosteroids and immunomodulating drugs is needed $(17,40,91)$. UV treatment is also an effective alternative $(65,86)$. Topical and systemic antibacterial treatment is used in patients with signs of bacterial infections. Antifungal therapy is used in patients with signs of a fungal infection. However, a more widespread use of antimycotics based on the role of the most yeasts as common allergens is still not commonly recommended.

The prognosis of $\mathrm{AD}$ is good; 60 to $70 \%$ of patients recover during childhood $(160,161)$. The prognosis is less positive in women, in patients who had severe $\mathrm{AD}$ as children, and in those with concurrent allergic rhinitis and/or asthma or a positive family history of AD.

\section{FUNGI INVOLVED IN ATOPIC DERMATITIS}

Not only bacteria, especially $S$. aureus, but also fungi may play an important role as aggravating factors in AD. The majority of studies in AD and fungi deal with the Malassezia yeasts, probably because these yeasts are the most important fungi in $\mathrm{AD}$.

\section{Malassezia}

Historical. The earliest report of Malassezia-like yeasts was made by Eichstedt in 1846 (31). In 1853, Robin described round cells on the skin of patients with dandruff (124). In 1873, Rivolta described the presence of round double-contoured budding cells in a patient with psoriasis (121). In 1874, Malassez noticed budding cells of various shapes in the stratum corneum of patients with various skin diseases, and the name Malassezia furfur was proposed by Bailon in 1889 (10). However, Malassez was never able to culture the microorganism. Von Sehlen (153a) and Unna (153) were probably the first to culture the organism.

The genus name Pityrosporum was proposed by Sabouraud in 1904 (127). In 1913, Castellani and Chalmers were able to culture the organism and characterize the growth properties (25). They introduced the name Pityrosporum ovale, and their description of the organism is based on the characteristics of the fungus both in skin scales and in the laboratory (25). The name $P$. pachydermatis was introduced by Veidman in 1925 for a nonlipophilic species of the genus Pityrosporum isolated primarily from animals (140). In 1951, Gordon isolated a round, double-contoured yeast that produced spherical to oval buds from both pityriasis versicolor scales and normal skin $(45,46)$. The name he gave the organism, $P$. orbicualre, is based primarily on the micromorphology. However, later studies have shown that the round and oval forms of the organism are not stable (12) and that the two forms can change from one to the other on special culture media or under special culture condi- 


\section{Typing of Malassezia species}

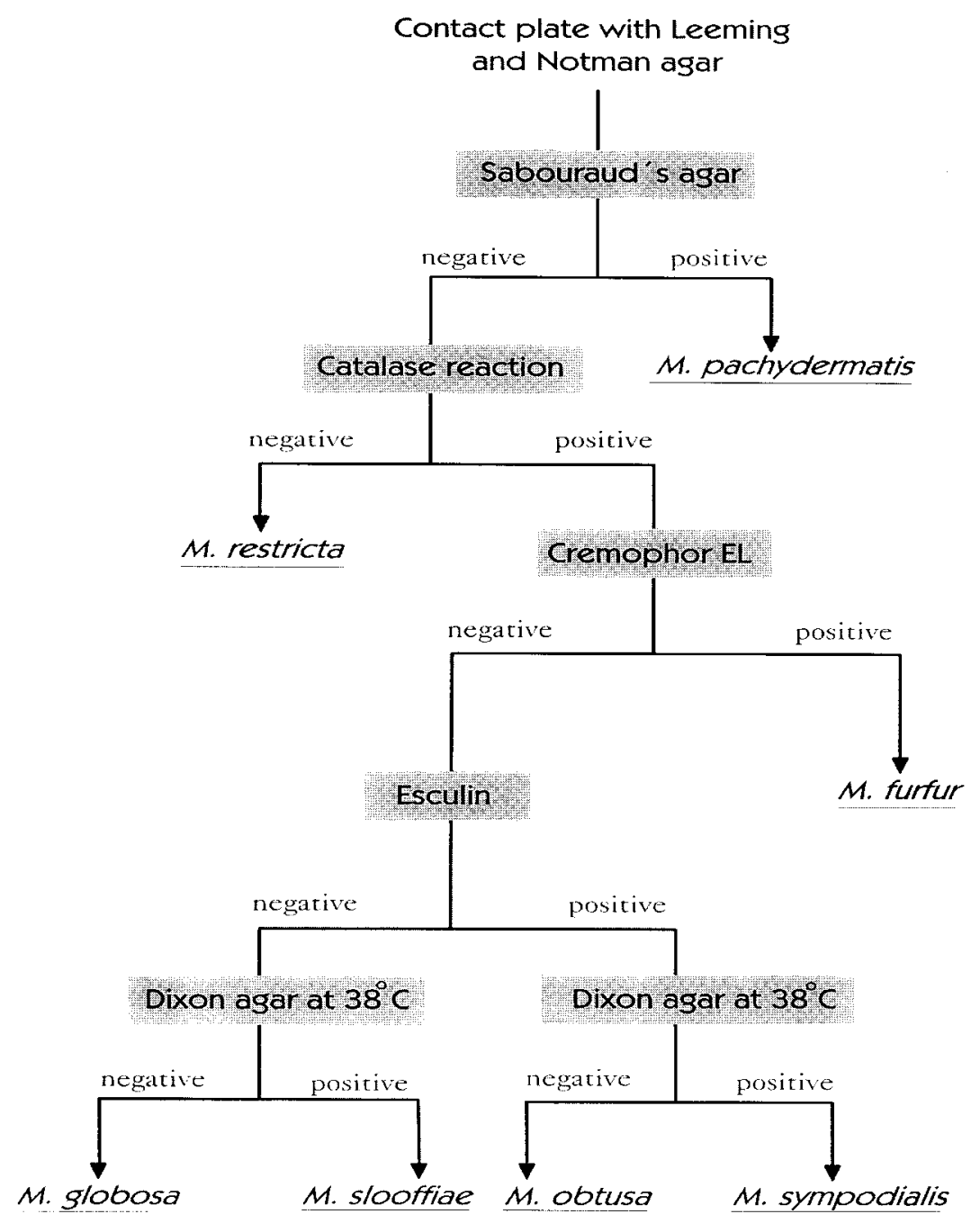

FIG. 1. Typing system for the Malassezia yeasts.

tions (128) and when experimental infections are induced in rabbits (34).

The genus Malassezia has in a taxonomic revision been placed in the kingdom Fungi, division Basidiomycota, class Hymenomycetes, order Tremellales and family Filobasidium uniguttulatum (61). Molecular biology using rRNA sequence analysis and nDNA comparisons, as well as $\mathrm{G}+\mathrm{C}$ content in extracted DNA, has clearly divided the genus Malassezia into seven different species $(48,49)$. Today this genus consists of $M$. furfur (10), M. pachydermatis (140), M. sympodialis (48, 49), $M$. globosa, M. slooffiae, M. restricta, and M. obtusa (48, 49).

Morphology and growth requirements. The seven Malassezia species exhibit typical morphological and physiological features $(48,49)$. They reproduce by unilateral budding, leaving prominent scars on the mother cells (61). The yeast cells may be bottle-shaped, globose, ovoid, or cylindrical. Buds may be formed on a narrow or wide base. The most interesting feature of the genus Malassezia is the presence of a thick multilayered cell wall whose inner surface is corrugated. The protoplasmic membrane is firmly attached to the inside of the cell wall. The major components of the cell wall are mannoproteins (75 to $80 \%$ ), lipids (15 to $20 \%$ ), and chitin (1 to $2 \%$ ) (105). It is thought that the immunomodulatory capacity of the Malassezia yeasts are related to cell wall lipids.

Using various physical, chemical and metabolic characteristics, the Malassezia species can be identified $(48,49)$. We have recently developed a modification of previous identification systems by which the seven different Malassezia species easily can be identified (Fig. 1). The advantages of this system are that it is easier and faster and that Tween reaction, which is often difficult to read, is not necessary. We always isolate the Malassezia yeast using the media described by Leeming and Notman (87). This medium contains, among other ingredients, ox bile, glycerol, glycerol monostearate, Tween 60 , and wholefat cow's milk. Compared to other culture media, this was the most effective for isolation of the Malassezia yeasts (15).

Various morphological and physiological criteria can be used to characterize the Malassezia yeasts (Fig. 1) $(48,49,61)$. 
M. pachydermatis is nonlipophilic and can be cultured on lipidfree culture media. Cells are small and ovoid with a very broad base, and they never produce filaments. $M$. furfur can vary in micromorphology, producing cells that are long cylindrical ovoid or even globose. A few strains may produce filaments spontaneously or during special culture conditions. $M$. furfur is catalase positive, does not split esculin, grows on Dixon agar at $38^{\circ} \mathrm{C}$, and is capable of growing in the presence of Cremophor. M. sympodialis has small ovoid cells. It is catalase positive, splits esculin, grows on Dixon agar at $38^{\circ} \mathrm{C}$, and is not capable of growing in the presence of Cremophor. M. slooffiae has short cylindrical cells appearing ovoid under the light microscope with buds formed on a broad base. It is catalase positive, does not split esculin, grows on Dixon agar at $38^{\circ} \mathrm{C}$, and is not capable of growing in the presence of Cremophor. M. obtusa has large cylindrical cells with a broad base. It is catalase positive, splits esculin, does not grow on Dixon agar at $38^{\circ} \mathrm{C}$, and is not capable of growing in the presence of Cremophor. M. globosa has stable spherical cells. Buds are formed on a narrow base and might elongate to form germination tubes or even short filaments. It is catalase positive, does not split esculin, does not grow on Dixon agar at $38^{\circ} \mathrm{C}$, and is not capable of growing in the presence of Cremophor. $M$. restricta has small spherical or ovoid cells with a relatively narrow base. It is catalase negative, does not split esculin, does not grow on Dixon agar at $38^{\circ} \mathrm{C}$, and is not capable of growing in the presence of Cremophor.

Distribution and isolation. The Malassezia yeasts are members of the normal human cutaneous flora $(36,41,46)$. However, there is great variation in the density and presence in various skin locations $(35,88)$, in children compared to adults $(15,33)$, and in normal skin compared to diseased skin $(37,45)$. The Malassezia yeasts are also associated with several skin diseases such as pityriasis (tinea) versicolor, Malassezia folliculitis, seborrheic dermatitis, atopic dermatitis, and some forms of confluent and reticulate papillomatosis (Gougerot-Carteaud syndrome) $(33,41)$. They may even be involved in systemic diseases $(33,120)$.

In 1951, Gordon isolated lipophilic yeasts from both normal healthy volunteers and patients with pityriasis versicolor (45, 46). Using direct microscopy or culture, Roberts found what he called $P$. ovale on the scalp and on the chest of $97 \%$ and 92 to $100 \%$ normal healthy adults, respectively (122). He also isolated the yeast in large numbers from patients with pityriasis versicolor (123). In a quantitative culture study, using a modification of the Williamson-Kligman scrub technique, Malassezia yeasts were cultured from clinically normal skin of the on the chest, back, upper arm, lower leg, and dorsal aspect of the hand (35). The highest count was found on the back, and the lowest was found on the hand. An easy semiquantitative method is to use contact plates $(13,15)$. This was first described in detail in 1987 (13). However, better results have later been obtained using a modification of the culture medium developed by Leeming and Notman $(15,87)$. Leeming et al. were able to culture the Malassezia yeasts from 20 different body sites, with the largest numbers being found on the scalp and upper trunk (88). We found in a culture study of adults that the density of the Malassezia yeasts decreased with increasing age (13). Although the number of yeast cells is larger in adults, the yeasts can also be cultured from children $(15,35)$.
Several studies have demonstrated that the Malassezia yeasts can be cultured in newborns.

The Malassezia yeasts can be cultured not only from healthy skin but also from patients with various skin diseases $(35,36$, 41). The number of yeasts is not always increased, but other mechanisms may be important in the pathogenesis. The yeast may induce immunological changes or behave as irritants, and then a reduction even of a relatively small number of yeast cells will result in an improvement. Quantitative or semiquantitative cultures can therefore be used to monitor the effect of treatment or changes in predisposing factors.

Only a few culture studies have been done using the new classification of the Malassezia yeasts (32, 51, 52, 76, 107). However, it is important to look at the distribution of the various Malassezia species not only on healthy skin but also on the skin of patients with Malassezia-associated skin diseases.

Nakabayashi et al. isolated various Malassezia species from the skin of healthy individuals and from patients with pityriasis versicolor, seborrheic dermatitis, and atopic dermatitis in Japan (107). The yeasts were cultured qualitatively using swabs and Dixon's agar medium, and specimens for culture were taken from the scalp, face and trunk. Cultures were negative in $14 \%$ (pityrasis versicolor) to $50 \%$ (healthy individuals) of cases. M. globosa was the most commonly isolated species from healthy volunteers, patients with pityriasis versicolor, and nonlesional skin of patients with AD. M. furfur was the most commonly isolated species from patients with seborrheic dermatitis and lesional skin of patients with AD.

In a study by Kim and Kim, the Malassezia yeasts were isolated qualitatively from various body regions in normal healthy volunteers from South Korea (76). All six lipophilic species were cultured. However, there was a great variation in the incidence of these yeasts, with $M$. restricta being the most commonly isolated species from the scalp and forehead and $M$. globosa being the most commonly species isolated from the chest and the back.

In two reports from Canada, Gupta et al. have isolated the various Malassezia yeasts from both healthy individuals and patients with various Malassezia-related skin diseases $(51,52)$. In the first study, the Malassezia yeasts were isolated qualitatively, in patients with pityriasis versicolor, by scraping skin flakes into a paper bag, and later the flakes were transferred to Leeming and Notman agar and to Littman agar supplemented with olive oil (51). A total of 111 samples were obtained from patients in Ontario, Canada, and 18 were from patients in other countries (South Africa, Hong Kong, Portugal, Brazil, and Hawaii). In the patients from Canada, M. sympodialis was isolated in 59\%, M. globosa was isolated in 25\%, and M. furfur was isolated in $11 \%$. In patients from other countries, $M$. globosa was the dominating species, being cultured in $62 \%$. In the other study, the Malassezia yeasts were isolated semiquantitatively, using contact plates with the Leeming and Notman agar (52), from both healthy volunteers and patients with pityriasis versicolor, seborrheic dermatitis, AD, and psoriasis. All the lipophilic Malassezia species were isolated. M. sympodialis was the dominant organism in healthy controls and in patients with pityriasis versicolor and $\mathrm{AD}$, while $M$. globosa was the dominant species in patients with seborrheic dermatitis and psoriasis. The number of yeast colonies was largest in lesional skin from patients with pityriasis versicolor but was not statis- 
tically significantly larger than in nonlesional skin or in skin from healthy individuals. However, the number of colonies of Malassezia was statistically significantly larger in both healthy individuals and patients with pityriasis versicolor than in patients with seborrheic dermatitis, AD, and psoriasis.

Erchiga et al, cultured the various Malassezia species qualitatively using Dixon agar from both lesional and nonlesional skin of patients with pityriasis versicolor in Spain (32). Cultures were positive in all patients. M. globosa, either alone or in combination with $M$. sympodialis, was the dominant species, being cultured in $97 \%$ of patients; M. sympodialis was cultured in $32 \%$, either together with M. globosa or alone (only three patients). In nonlesional skin from the shoulders, Malassezia species were cultured in $47 \%$ of the patients and M. sympodialis was the dominant species, being cultured in $42 \%$ of all cultures.

According to these five reports, M. sympodialis, M. globosa, and $M$. furfur were the most commonly isolated Malassezia species. However, there were differences in the species that was most commonly isolated, not only between healthy individuals and patients with various diseases but also between results from different countries $(32,51,52,76,107)$.

The Malassezia yeasts as pathogens. As mentioned above, the Malassezia yeasts are opportunistic pathogens, and under the influence of various predisposing factors, they are involved in several diseases $(36,41)$.

In pityriasis versicolor, under the influence of exogenous or endogenous predisposing factors, the yeast changes from the blastospore form to the mycelial form $(38,39)$. Pityriasis versicolor is a chronic superficial disease that usually affects the upper trunk, neck, or upper arms. It has a worldwide distribution. In tropical areas, it has been found in 30 to $40 \%$ of the population. However, the incidence is much lower in temperate climates. The diagnosis is based primarily on a typical clinical picture in combination with bright yellow fluorescence under Wood's light examination and direct microscopy. Direct microscopy is of major importance, and the round or oval budding cells and hyphae can easily be identified. There are numerous ways of treating pityriasis versicolor, both topically and with systemic drugs (42). However, the high rate of recurrence, affecting $60 \%$ of patients after 1 year and $80 \%$ after 2 years, is an outstanding problem. Consequently, a prophylactic treatment regimen is necessary to avoid recurrence.

Malassezia folliculitis is a chronic disease characterized by pruritic follicular papules and pustules located primarily on the upper trunk, neck, and upper arms $(7,41)$. Under the influence of predisposing factors, Malassezia folliculitis may be explained by an extensive growth of Malassezia in the hair follicle. The inflammation may be due both to products of the yeast and free fatty acids produced as a result of the lipase activity of the yeast $(7,41,43)$. The diagnosis is based on a typical clinical picture of itchy papules and pustules as the predominant symptoms, direct microscopy, and the effect of antimycotic treatment $(7,41)$. The effect of antimycotic treatment is often dramatic. Most cases responds well to topical treatment, but systemic treatment with e.g. itraconazole or fluconazole has been used in difficult cases (42). Lesions and itching recur in most patients if treatment is not maintained intermittently. Therefore, a prophylactic treatment schedule, such as topical treatment once or twice a week, is recommended.
Seborrheic dermatitis is characterized by red scaly lesions located predominantly on the scalp, face, and upper trunk. There are now many studies indicating that the Malassezia yeasts play an important role in seborrheic dermatitis $(6,14$, 36, 41, 42, 43). Many of these are treatment studies which describe the effectiveness of antimycotics, paralleled by a reduction in number of the Malassezia yeasts, whereas recolonization leads to a recurrence of seborrheic dermatitis. The increased incidence of seborrheic dermatitis in patients with immunosuppressive disorders suggests that the relationship between Malassezia and the immune system is important, but the exact mechanism involved is still unknown. Studies designed to investigate this mechanism in patients with seborrheic dermatitis fall into four areas $(6,43)$ : the humoral response to Malassezia, lymphocyte transformation response to Malassezia extract, T helper (CD4)/T suppressor (CD8) cell ratios, and cytokine responses. However, studies in all of these areas have given inconsistent results, and the local reaction in the skin may give a better answer. In a recent study, the number and type of inflammatory cells and mediators from lesional and healthy skin in patients with seborrheic dermatitis were been studied (43). Staining was often more intense when Malassezia yeasts cells were present. An increase in NK- and CD16-positive cells in combination with complement activation indicates that an irritant or nonimmunogenic stimulation of the immune system is important. With the interleukins, an increase in the production of inflammatory interleukins and an increase in the regulatory interleukins for both Th1 and Th2 cells were seen. The immune response described for cutaneous C. albicans infections (126) has similarities to the skin reactions found in seborrheic dermatitis (43).

\section{Atopic Dermatitis and the Malassezia Yeasts}

Distribution of the Malassezia yeasts. Many reports clearly indicate the role of Malassezia in AD, especially AD located to the head and neck area in adults $(19,26,29,30,41,62,66,69$, $74,83,98,109,125,131,132,135,136,137,148,149,154)$. The Malassezia yeasts have been cultured from patients with AD with the same frequency as from healthy individuals $(19,41$, 52). In one study of children from newborn to the age of 20 years, the Malassezia yeasts were isolated from lesional and nonlesional skin, from the same region, as well as from normal skin of the forehead of patients with AD (19). Normal skin on the forehead in age- and sex-matched individuals with rhinoconjunctivitis and/or asthma and healthy volunteers served as controls. Cultures did not differ significantly among the three groups or between lesional and nonlesional skin. There was, however, a difference between the age groups. Cultures were positive in 5 to $15 \%$ of children aged up 10 years and in 65 to $100 \%$ of 11 - to 20 -year-old persons. In a study of adult patients with AD involving the scalp and neck, Malassezia samples were taken from lesional skin of the forehead and cultured on Leeming and Notman agar in contact plates (20). Culture was positive in $83 \%$ of cases.

These two studies were performed before the new taxonomy for the Malassezia yeasts was introduced. In the above-mentioned study by Nakabayashi et al., they were able to classify the Malassezia yeasts (107). Samples were taken from lesional and nonlesional skin from the scalp, face, and trunk. In lesional 
skin the most commonly isolated species was $M$. furfur, which was cultured in $21 \%$ of samples. M. globosa was cultured in $14 \%$, M. sympodialis was cultured in $7 \%$, M. slooffiae was cultured in $4 \%$, and cultures were negative in $46 \%$. In nonlesional skin, the most commonly isolated species was $M$. globosa (33\%); M. furfur was cultured in $11 \%$ of samples; $22 \%$ were unknown species or contaminated cultures, and $33 \%$ of samples were culture negative.

Gupta et al. cultured the Malassezia yeasts semiquantitatively, using the Leeming and Notman culture medium in contact plates, from patients with various skin diseases and healthy controls (52). In patients with $\mathrm{AD}$, the total number of isolated colonies was significantly larger from nonlesional skin than from to lesional skin. The number of colonies from both lesional and nonlesional skin was significantly smaller than the number of colonies from healthy individuals, patients with pityriasis versicolor (both lesional and nonlesional skin), and nonlesional, but not lesional, skin of patients with seborrheic dermatitis. In AD there were no differences in the percentages of the various Malassezia species isolated from lesional and nonlesional skin. M. sympodialis was the most commonly isolated species, being cultured in $51 \%$ of the patients, $M$. globosa was cultured in $18 \%, M$. furfur and M. obtusa were each cultured in $10 \%$, M. restrticta was cultured in $8 \%$, and $M$. slooffiae was cultured in 3\%. The majority of Malassezia yeasts were cultured from the forehead and the trunk. In an English abstract from a paper otherwise written in Russian, Arzumanian stated that $M$. sympodialis was the most commonly isolated species isolated from both patients with $\mathrm{AD}$ and healthy individuals (5).

In a recently completed multicenter study in Sweden, involving the Departments of Dermatology in Gothenburg, Lund, and Stockholm and the Department of Clinical Immunology, Karolinska Hospital, Stockholm, we cultured the Malassezia yeasts from 125 patients with $\mathrm{AD}, 16$ with seborrhec dermatitis, and 30 healthy controls (66a). Cultures were performed using the Leeming and Notman agar (87) in contact plates from normal-appearing skin of the upper back and, in AD and seborrheic dermatitis patients, also from lesional skin. Cultures were positive in $56 \%$ of patients ( 70 of 125 ) with AD, $88 \%$ of patients with seborrheic dermatitis, and $83 \%$ of healthy controls. In patients with $\mathrm{AD}$, M. sympodialis was cultured in $40 \%$, M. obtusa was cultured in $25 \%$, M. globosa was cultured in $23 \%$, M. slooffiae was cultured in $6 \%, M$. furfur was cultured in $4 \%$, and $M$. restricta was cultured in $2 \%$. The same frequency of the Malassezia yeasts was seen in healthy controls. However, in patients with seborrheic dermatitis, M. obtusa was cultured in $30 \%$ and M. sympodialis was cultured in $30 \%$.

Immunology. (i) Skin prick test for type I hypersensitivity. A positive skin prick test (SPT) was first reported in 1958 among a group of AD patients (63). In 1983, Clemmensen and Hjorth described a positive effect of oral ketoconazole in the treatment of adult patients with AD localized to the head and neck area and with positive SPTs to Malassezia (26). In 1985, Waerstad and Hjorth investigated 741 patients with AD and found a positive Malassezia SPT only in patients with active eczema and most frequently in patients with head and neck dermatitis (28\%) (154). Patients with other atopic manifestations such as rhinitis or asthma but without $\mathrm{AD}$ were negative in SPT to Malassezia.
Kieffer et al., in collaboration with our group in Gothenburg, reported a positive SPT to Malassezia in $79 \%$ of adult patients with AD localized to the head and neck area (74). The SPT was positive in $45 \%$ of patients with $\mathrm{AD}$ but without the head and neck distribution, and patients with seborrhoeic dermatitis were negative. These percentages are much higher than those obtained by Waersted and Hjorth. However, several children were included in the report by Waerstad and Hjorth. The Malassezia extract used in this and the two earlier studies is a protein extract prepared by ALK Laboratories, Copenhagen, Denmark. The same extract has also been used for a histamine release assay (Lucotest-HR; Lundbeck Diagnostics, Copenhagen, Denmark) measuring the release of histamine from basophils after stimulation with the antigen. The results of histamine release after stimulation with Malassezia extract paralleled the results obtained with the SPT (74).

Rokugo et al. found that the results of the SPT vary according to the age of the patients (125). Among AD patients younger than 10 years, $39 \%$ were positive in SPT, while $64 \%$ of patients older than 10 years were positive. Wessels et al. found positive SPTs to Malassezia in $84 \%$ of adult patients with AD (157). In a study by Broberg et al., children with AD, rhinitis and/or asthma without $\mathrm{AD}$, and healthy controls were investigated (19). A total of 60 children in each category were included, and the children were divided into four groups: 0 to 5 years, 6 to 10 years, 11 to 15 years, and 16 to 21 years, with 15 in each group. SPTs to Malassezia were positive in $23 \%$ of patients with $\mathrm{AD}, 0 \%$ of patients with rhinitis and/or asthma, and $8 \%$ of healthy controls (three subjects). Among the patients with $\mathrm{AD}, 1$ of 15 patients in the age group from 0 to 5 years was SPT positive compared to 6 of $15(40 \%)$ in the age group from 16 to 21 years.

Kim et al. have performed an SPT with an $M$. furfur extract in 80 young adult patients with the head and neck distribution of $\mathrm{AD}$ and compared the results to those obtained for controls without AD (75). A total of $45 \%$ showed positive SPT responses, and the severity score of the head and neck lesions in the $M$. furfur SPT-positive group was significantly higher than in the $M$. furfur-negative group. In another study, Devos and van der Valk studied patients with $A D$, with and without the head and neck distribution, using SPT with a Malassezia extract and other procedures (28). In a total of 92 patients with $\mathrm{AD}$ (the majority were young adults), the SPT was positive in $40 \%$. However, only $6 \%$ of the patients with the head and neck distribution of $\mathrm{AD}$ were positive. This is contradictory to all earlier studies, in which patients with the head and neck distribution of AD showed the largest number of positive SPTs to Malassezia (19, 26, 74, 154).

In the above-mentioned Swedish multicenter study, we also performed SPT with extracts of Malassezia, the recombinant allergens Mal f 1, Mal f 5, Mal f 6, and a mix of these recombinant allergens $(96,137)$ in patients with $\mathrm{AD}$, patients with seborrheic dermatitis, and healthy controls; $74 \%$ of the AD patients had the head and neck distribution. We found that $57 \%$ of the $\mathrm{AD}$ patients were positive to the extract or recombinant allergens; $52 \%$ were positive to the Malassezia extract. However, $56 \%$ of patients with the head and neck distribution of $\mathrm{AD}$ were positive to the extract compared to only $36 \%$ of the patients without the head and neck distribution of AD. None of the patients with seborrheic dermatitis or the healthy 
TABLE 1. SPT reactions to the Malassezia yeasts in patients with $\mathrm{AD}$

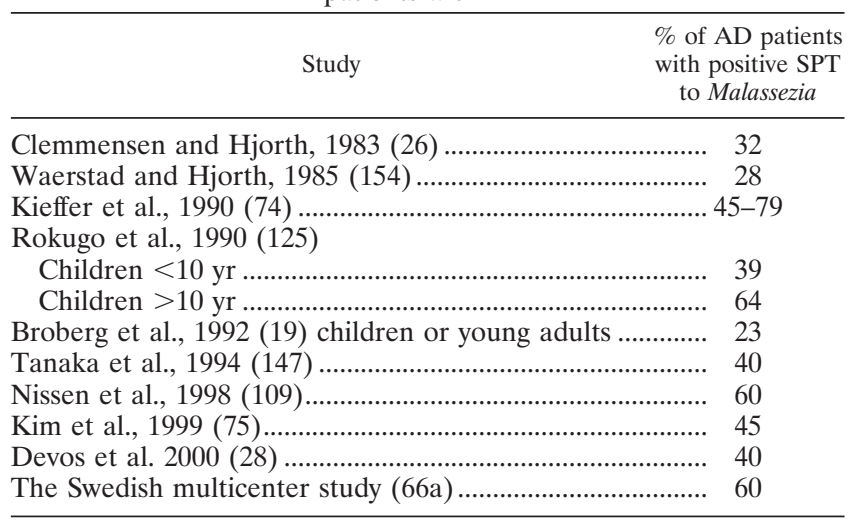

controls were positive. All readings were done in a controlled double-blind design.

In summary, positive SPT to Malassezia is found primarily in adult patients with $\mathrm{AD}$ and especially in adult patients with the head and neck distribution of AD (Table 1).

(ii) Specific IgE antibodies to the Malassezia yeasts. The first paper describing specific IgE antibodies to the Malassezia yeasts was published in 1991 (69). Specific antibodies were found especially in patients with $\mathrm{AD}$ and less commonly in patients with other atopic manifestations. This was later verified by other groups using various extract from Malassezia (19, $29,30,66,69,157,166)$. In the study by Broberg at al., specific $\mathrm{IgE}$ antibodies were found in eight children with $\mathrm{AD}$, five in the age group from 16 to 21 years, and only one patient with rhinitis and/or asthma (19). In another study with children (4 to 16 years old), $22 \%$ of patients with $\mathrm{AD}$ had $\mathrm{IgE}$ antibodies against Malassezia (97). In these patients, the AD was generally worse than in those without specific Malassezia IgE antibodies. The head and neck distribution of $\mathrm{AD}$ was also more common and the onset of AD occurred earlier in life than in specific IgE-negative children.

Back et al. found in a study of 74 adult patients with AD that $44 \%$ had specific Malassezia IgE antibodies (8). No antibodies were found in patients with seborrheic dermatitis (11) or healthy controls (39). The presence of specific Malassezia IgE antibodies correlated with elevated total IgE levels.

In the study by Kim et al., $68 \%$ of patients with the head and neck distribution of $\mathrm{AD}$ had specific $\mathrm{IgE}$ antibodies against Malassezia (75). The clinical severity and total IgE level in serum for these patients were greater in patients with Malassezia-specific IgE antibodies than in patients with a negative response. Devos and van der Valk also studied the presence of specific IgE antibodies in patients with AD (28). However, In contrast to their SPT results, mentioned above, they found that $100 \%$ of patients with the head and neck distribution of AD had Malassezia-specific IgE antibodies compared to only $14 \%$ of AD patients without the head and neck distribution.

Savolainen et al. recently described specific and nonspecific humoral cellular and cytokine responses to Malassezia and Candida in AD patients (135). Fifteen AD patients and 7 healthy controls were included. The total IgE level in serum was clearly higher in $\mathrm{AD}$ patients than in controls. The Malassezia- and C. albicans-specific IgE level was also signifi- cantly increased in AD patients compared to controls. Malasse$z i a$ was a stronger inducer of $\operatorname{IgE}$ responses, and C. albicans more strongly induced $\mathrm{IgG}$ responses. However, there were no significant differences in Malassezia- and C. albicans-specific IgG levels between the groups. The rest of the study is discussed in the section on cellular and interleukin responses (see below).

Mayser and Gross have studied the presence of specific IgE antibodies against various Malassezia species (104). The presence of specific antibodies against $M$. sympodialis, $M$. furfur, and the commercially available Malassezia extract was studied in patients with $\mathrm{AD}$, seborrheic dermatitis, pityriasis versicolor, and hymenoptera allergy and healthy controls. The allergens alone as well as various combinations were included. It was found that $35 \%$ of $\mathrm{AD}$ patients had specific $\operatorname{IgE}$ antibodies against one or several allergens, $12 \%$ of patients with seborrheic dermatitis were positive, $8 \%$ of patients with hymenoptera allergy were positive, and none of the patients with pityriasis versicolor or the healthy controls were positive. For patients with $\mathrm{AD}$, the largest number of positive results was seen in patients with the head and neck distribution of AD. There was also strong correlation between specific IgE antibodies and the total IgE level. Differences in the type and extent of sensitization were also found among the Malassezia yeasts. M. sympodialis and the commercially available Malassezia extract were almost equally positive, while the frequency of sensitization to $M$. furfur was lower. The commercially available Malassezia was typed using the new classification and found to be $M$. sympodialis. M. sympodialis is more common on the skin of patients with AD and it therefore a better allergen for testing than $M$. furfur.

In the Swedish multicenter study, mentioned above, specific serum IgE anribodies to the Malassezia extract was found in $45 \%$ of patients with AD; again, patients with the head and neck distribution of $\mathrm{AD}$ had the highest number of reactions (55\%); $40 \%$ of the AD patients had both specific Malassezia $\mathrm{IgE}$ antibodies and positive SPT. Patients with seborrheic dermatitis and healthy controls were negative. RMal f 1 , rMal f 5, and rMal $\mathrm{f} 6$ specific serum IgE antibodies were found in 19, 28 , and $25 \%$, respectively. Specific serum IgE -antibodies to the recombinant Malassezia antigens, alone or together, were found in $40 \%$ of the patients. In contrast to the extract, moderately strong correlations were found between SPT (in millimeters) and specific serum IgE level for rMal f 1, rMalf 5, and rMal f 6.

Specific Malassezia IgE antibodies were found in 20 to $100 \%$ of patients with AD. The prevalence was lower in children, higher in adults, and highest in adult patients with the head and neck distribution of AD. Table 2 summarizes the specific Malassezia serum IgE antibodies found in various studies.

(iii) Characterization of antigens. Several IgE binding components of Malassezia have been isolated (29, 30, 62, 66, 69, 70, $98,131,132,137,149,157,166,167)$. Three major allergen components from Malassezia were later identified using monoclonal antibodies (166). Two of them, a 67-kDa component and a $37-\mathrm{kDa}$ component, were proteins, and one, a 14-kDa component, was probably of carbohydrate origin. In other studies, allergen cross-reactivity between Malassezia and $C$. albicans has been found $(29,30,98,131)$. According to Zargari et al., the 14-kDa component may be found in both yeasts 
TABLE 2. Specific IgE serum antibodies to the Malassezia yeasts in patients with $\mathrm{AD}$

\begin{tabular}{lcr}
\hline \multicolumn{1}{c}{ Study } & $\begin{array}{c}\% \text { of AD patients with } \\
\text { specific Malassezia IgE } \\
\text { antibodies }\end{array}$ \\
\cline { 2 - 3 } & Children & Adults \\
\hline Johansson et al., 1991 (69) & 19 \\
Broberg et al., 1992 (19) & 13 & \\
Lindgren et al., 1995 (97) & 22 & 44 \\
Back et al., 1995 (8) & & 93 \\
Nissen et al., 1998 (109) & 68 \\
Kim et al., 1999 (75) & 54 \\
Scalabrin et al., 1999 (135) & & 100 \\
Devos et al., 2000 (28) & & 34 \\
Mayser and Gross, 2000 (104) & & 60 \\
Savolainen et al., 2001 (140) & & 45 \\
The Swedish multicenter study (66a) & & \\
\hline
\end{tabular}

(166). Jensen-Jarolim et al. have also tried to characterize various components of Malsssezia, and they described 9- and $15-\mathrm{kDa}$ components that probably are nonprotein carbohydrate components of the cell wall (66). However, Savolainen et al. have described protein components common to both Malassezia and C. albicans (131, 132). In 1997, Lintu et al. have described IgE antibodies to both protein and mannan antigens of Malassezia in sera from patients with AD (98). Lintu et al. found other major components from those found by Zargari et al. In another paper, Lintu et al. described cross-reacting $\operatorname{IgE}$ and IgG antibodies to both Malassezia, C. albicans, Saccharomyces cerevisiae, and, to some extent, Cryptococcus albidus (100). In the IgE response, the main cross-reacting pattern was the mannan region and Malassezia was the most potent inhibitor of the IgE-binding components. In contrast, C. albicans was found to be the most important inducer of $\operatorname{IgG}$ antibodies.

There are several explanations for the different results obtained. The technique used is important, and the strain of Malassezia used is also important. The length of the culture period may also be of importance (167). The protein content of the extract was highest after 2 days but gradually declined after day 4. On the other hand, the carbohydrate content remained fairly constant. The stability of the extracts is also influenced by the storage period and conditions (99). The stability of Malassezia protein extracts stored, even at $4^{\circ} \mathrm{C}$, for more than 1 month was poor. The 9-kDa component was more stable than the $20-\mathrm{kDa}$ component and, the $96-\mathrm{kDa}$ bands in particular were far more labile. In none of these reports were the Malassezia yeasts classified according to the new taxonomy.

Antigenic bands against both $M$. sympodialis and $M$. furfur were found in sera from patients with AD (103). The molecular masses of the most important bands were 15, 22, 30, 37, 40, 58, 79, 92, 99, and $124 \mathrm{kDa}$ for M. sympodialis and 15, 25, 27, 43, 58, 92, 99, and $107 \mathrm{kDa}$ for $M$. furfur. Control sera were negative. When $M$. furfur-positive sera were preincubated with M. sympodialis, the clear band of $15 \mathrm{kDa}$ disappeared, indicating a possible cross-reaction of the antibodies. However, this study clearly demonstrates that there are differences between different strains of Malassezia and that differences in results may be due to the use of different strains.

Schmidt et al. have identified the complete cDNA sequence and expression of one major allergen protein of Malassezia
(137). According to the WHO/IUS nomenclature, this recombinant allergen is named Mal $\mathrm{f} 1$. Yasueda et al. have isolated two additional major recombinant allergens, named Mal $\mathrm{f} 2$ and Mal f 3 (165), and Onishi et al. have isolated the Mal f 4 recombinant allergen (114). Recently, Rasool et al. isolated and characterized Mal f 7, Mal f 8, and Mal f 9 (119). However, like the allergen Mal $\mathrm{f} 1$, these three recombinant allergens were prepared from the ATCC strain 42132 of $M$. furfur (formerly $P$. orbiculare). This Malassezia strain is not $M$. furfur but $M$. sympodialis (104). I was the one who donated this strain to the ATCC in 1979, and I have now retyped it according to the new taxonomy. According to this, I have also retyped it as $M$. sympodialis. These recombinant allergens should therefore be named Mal sy (1 etc.). The reference strain used by Yasueda et al. (165) and by Onishi et al. (114) are from another reference laboratory (strain 2782 from Teikyo Institute for Medical Mycology) and is named $M$. furfur. I have not personally confirmed that this species is $M$. furfur.

Recently, Koyma et al. isolated three major components of M. globosa from extracts of this yeast (82). These antigens were named Mal g 46a, Mal g 46b, and Mal g 67. Mal g 46b was found to be the major antigen, and it reacted only with sera from patients with $\mathrm{AD}$ and with none of the sera from patients with seborrheic dermatitis, pityriasis versicolor, or chronic urticaria or healthy controls. Mal g 46b reacted with $69 \%$ of the sera from patients with AD. Mal g $46 \mathrm{~b}$ reacted with $83 \%$ of sera containing IgE antibodies to $M$. globosa. In a lectin blot with concanavalin A, both Mal g 46 a and Mal g 46 b reacted with concanavalin A, indicating that these antigens were glycoproteins containing mannose chains in the molecules. When species specificity was tested, the antibody reacted strongly with $M$. globosa. A slight reaction was seen with $M$. restricta, but no reaction was seen with $M$. sympodialis, $M$. furfur, or $M$. slooffiae. Also, no reaction was seen with $C$. albicans. In the Japanese population, this antigen may be more important that antigens against, e.g., M. sympodialis, because M. globosa is more commonly cultured from AD patients in Japan (107).

(iv) Cellular and cytokine responses. Both in vitro and in vivo studies of cellular and cytokine responses have been performed. In parallel to SPT, several skin patch test experiments have been performed for investigation of a delayed-type hypersensitivity to the Malassezia yeasts.

Rokugo et al. found many patients with $\mathrm{AD}$ who were patch test positive to a Malassezia extract (125). However, they used the chamber scarification method, and Kieffer et al., using a standard test procedure without scarification, were not able to reproduce these large numbers of positive results (74).

Patch test reactions are often difficult to read in patients with AD. To evaluate the results of primarily aeroallergens, a special technique called the atopy patch test (APT) was developed (151). Briefly, the stratum corneum is stripped approximately 15 times with cellophane tape to achieve a slight increase in its permeability. The allergens are then applied on paper disks in Finn chambers ( $8 \mathrm{~mm}$; Epitest Ltd Oy, Tuusula, Finland) on normal-appearing skin of the back and covered with a nonirritating tape. The disks are removed after $48 \mathrm{~h}$, and the skin reaction is evaluated 24,48 , and $72 \mathrm{~h}$ after that. In a study by Tengvall-Linder et al., using this technique, 8 of 15 adult patients with $\mathrm{AD}$ were patch test positive to a Malassezia extract (151). However, none of 8 patients with seborrheic dermatitis 
or 15 healthy volunteers were positive. The AD patients with positive APT reactions had significantly higher specific Malassezia serum IgE antibody levels than did AD patients with negative reactions. Malassezia-specific IgE, but not total $\mathrm{IgE}$, levels correlated with the degree of APT response at $48 \mathrm{~h}$ in the whole group of $\mathrm{AD}$ patients. However, specific serum IgG levels did not differ significantly between the two groups of AD patients.

In the above-mentioned Swedish multicenter study, patients with $\mathrm{AD}$, patients with seborrheic dermatitis, and healthy controls were also subjected to APT with both the crude Malassezia extract and extracts containing the recombinant allergens Mal f 1, Mal f 5, and Mal f 6, both alone and in combination. Positive APT reactions were found in $38 \%$ of patients with $\mathrm{AD}, 7 \%$ of patients ( 1 patient) with seborrheic dermatitis, and none of the healthy controls. For the AD patients, positive APT reactions to rMal $\mathrm{f} 1$, rMal $\mathrm{f} 5$, and rMal $\mathrm{f} 6$ were found in 6,15 , and $10 \%$, respectively. No positive reactions were seen in patients with seborrheic dermatis or in healthy controls. The APT reactions differed among these three recombinant allergens. rMal f 5 gave the strongest reactions, and $75 \%$ of these patients were also SPT positive and had specific serum IgE levels.

Kröger et al. have measured the synthesis of various lymphokines as well as the $\mathrm{IgE}$ synthesis from peripheral blood mononuclear cells after stimulation with a Malassezia extract (83). They found that IL-4 and IL-10 synthesis was increased and IL-2 and gamma interferon (IFN- $\gamma$ ) synthesis decreased in patients with $\mathrm{AD}$ and with $\mathrm{RAST}^{+}$-specific serum IgE antibodies compared to healthy controls. IgE synthesis in the supernatants was only increased in patients with $\mathrm{AD}$ and with RAST $^{+}$-specific serum IgE antibodies.

The proliferative response in peripheral blood mononuclear cells (PBMC) to a Malassezia extract has been studied in 10 $\mathrm{AD}$ patients with specific serum IgE antibodies to Malassezia and in 6 healthy controls with no specific serum Malassezia IgE antibodies (148). The PBMC response to Malassezia was significantly higher in the $\mathrm{AD}$ group than in the control group. A response to a $C$. albicans extract was either not measurable or very low. $\mathrm{T}$ cells were obtained from peripheral blood and the skin by cloning from one AD patient with severe lesions and a high titer of specific Malassezia serum IgE antibodies. Several T-cell clones (TCC) from lesional skin showed a strong response to a Malassezia extract, whereas only a few TCC from peripheral blood were positive and none from nonlesional skin were positive. The response to a $C$. albicans extract was very low.

In the same study, freshly isolated PBMC produced only low cytokine levels of IL-4, IL-5, and IFN- $\gamma$ after 12 days of incubation with a Malassezia extract. When blood- and skin-derived Malassezia-reactive $\mathrm{CD} 4^{+}$TCC were tested for their production of IL-4, IL-5, and IFN- $\gamma$ after stimulation with phytohemagglutinin (PHA) and an anti-CD3 antibody, a variation of cytokine profile was produced. Th1, Th2, and Th0, cytokine profiles and a Th2/Th0 cytokine profile were found. The Th2like profile of Malassezia-reactive TCC derived from lesional skin indicates that Malassezia may play a role in maintaining IgE-mediated skin inflammation in AD. Incubation of TCC with a Malassezia antigen for 12 days induced measurable production of IL-5 but not IL-4 or IFN- $\gamma$. Nonstimulated and Malassezia-stimulated PBMC expressed similar levels of IFN- $\gamma$ mRNA at all time points. Stimulation of PBMC with Malasse- zia induced a time-dependent increase in gene expression for both IL-5 and IL-13, with maximal expression at $24 \mathrm{~h}$. Gene expression for these cytokines was hardly detectable in nonstimulated PBMC. Stimulation with anti-CD3 antibody induced a profound increase in the expression of genes for IFN- $\gamma$, IL-5, and IL-13 at 16 to $24 \mathrm{~h}$.

The same group has compared the immune response of AD patients to a Malassezia extract with that of healthy controls (150). The proliferative response of PBMC was significantly higher in the AD patients than in the healthy controls. Significantly higher levels of IL-5 was produced by PBMC from AD patients compared to healthy controls. Malassezia-reactive Tcell lines obtained after stimulation of PBMC by Malassezia antigen produced significantly higher levels of IL-4 and IL-5 after stimulation with anti-CD3 antibody and showed a higher IL-4/IFN- $\gamma$ ratio in AD patients than in healthy controls. These results indicate that the Malassezia yeasts may play a role in maintaining skin inflammation in AD.

Recently, Buentke et al. looked at the possible interaction of immature and mature antigen-presenting monocyte-derived dendritic cells (MDDCs) with Malassezia yeast cells and different Malassezia allergenic components (23). Internalization of Malassezia yeast cells and yeast components by immature MDDCs was found, and the results showed that a median of $94 \%$ of the immature CD1 ${ }^{\mathrm{a}+}$ MDDCs were Malassezia wholecell extract positive, $81 \%$ were positive to the recombinant antigen rMal f 5, and $93 \%$ were mannan positive. However, mature MDDCs were significantly less positive. The binding of the Malassezia extract and mannan was inhibited in a dosedependent manner by methyl- $\alpha$-D-mannopyranoside, suggesting uptake via the mannose receptor. This study demonstrated that human immature $\mathrm{CD} 1^{+}$MDDCs can efficiently take up Malassezia and allergenic components from the yeast in the absence of $\mathrm{IgE}$, implying that sensitization of $\mathrm{AD}$ patients to Malassezia can be mediated by immature dendritic cells in the skin. In their paper, the authors claimed that the Malassezia species used was $M$. furfur. However, the species was the above-mentioned ATCC isolate 42132, which both by myself and by Mayser and Gross (103), has been retyped as M. sympodialis. Specific IgE antibodies to $M$. sympodialis are more commonly seen in AD patients than are specific IgE antibodies to $M$. furfur (101).

Savolainen et al. have recently tried to characterize the Malassezia- and C. albicans-specific and -nonspecific humoral, lymphoproliferative, and cytokine responses in $\mathrm{AD}$ patients compared to healthy controls (135). Malassezia- and C. albicans-specific IgE levels and Malassezia-induced PBMC proliferation were elevated in AD patients. Both Malassezia- and $C$. albicans-specific IgE antibodies were detected in $\mathrm{AD}$ patients but not in healthy controls. The median titer of specific IgE response was significantly higher for Malassezia than for $C$. albicans. The IL-4/IFN- $\gamma$ ratio induced by Malassezia was higher than that induced by $C$. albicans. The PHA-induced IL-2 and IL-4 responses and the $C$. albicans-induced IL-5 response and IFN- $\gamma$ response were elevated in $\mathrm{AD}$ patients. Several correlations were found between total and yeast-specific IgE levels in serum, Malassezia-specific lymphoproliferation, PHA-induced IL-2, IL-4, and IL-5 levels, and C. albicansinduced IL-5 levels. The cytokine profiles found in this study for Malassezia were in parallel with and close to the results 
found by Tengvall-Linder et al. (149), and they support the role of a combination Th0-, Th1-, and Th2-responding Malassezia cells in the pathogenesis of AD. Differences in Malassezia responses obtained may occur because different Malassezia species were studied. In the study by Savolainen et al., Malassezia appears to be associated more with IL-4 responses and $C$. albicans appears to be associated more with IFN- $\gamma$ responses (135).

So far, the results of cytokine production of lymphocytes have been mentioned. In a paper by Watanabe et al., cytokine production by human keratinocytes after stimulation with cells of various Malassezia species has been described (156). The Malassezia species studied were $M$. pachydermatis, M. furfur, $M$. slooffiae, and M. sympodialis, and the cytokine production studied was that of IL-1 $\beta$, IL-6, IL-8, monocyte chemotactic protein-1 (MCP-1), and tumor necrosis factor-alpha (TNF- $\alpha)$. Cytokine production by keratinocytes after coculture with $M$. furfur was low or undetectable. In the supernatants cocultured with the other Malassezia yeasts, IL-1 $\beta$, IL- 6 , IL-8, and TNF- $\alpha$ were detected whereas the MCP-1 levels were low or undetectable. The cytokine levels were highest with $M$. pachydermatis. M. pachydermatits is cultured primarily from animals, and the dermatitis seen in animals is often more inflammatory than the human Malassezia-related diseases. There were even differences between the Malassezia yeasts in the number of yeast cells that were needed to start cytokine production.

Further studies are needed to explain differences in results between $\mathrm{AD}$ and other skin diseases as well as differences between the various Malassezia yeasts. A number of results for lymphocyte stimulation responses and cytokine production have been reported in the literature. Kroger et al. (83) found an increase in IL-4 and IL-10 production and a decrease in IL-2 and IFN-107 production in AD patients after stimulation with Malassezia extract; Tengvall-Linder et al. (150) and Savolainer et al. (135) found an increase in IL-4 and IL-5 production.

Treatment. In a study by Gupta et al., the in vitro susceptibility of the seven different Malassezia species against the azoles, ketoconazole, itraconazole and voriconazole and the allylamine terbinafine was tested (50). All of the Malassezia yeasts were highly sensitive to all three azole drugs. However, only $M$. pachydermatis and $M$. sympodialis were highly sensitive to terbinafine.

A double-blind crossover study by Clemmensen and Hjorth has shown that in patients with $\mathrm{AD}$, oral ketoconazole is statistically more effective than placebo (26). In an open study by Back et al. ketoconazole at $200 \mathrm{mg}$ once daily for 2 months followed by $200 \mathrm{mg}$ twice weekly for 3 months resulted in an improvement in clinical score in $\mathrm{AD}$ patients (8). There was also a reduction in the levels of both total $\mathrm{IgE}$ and specific $\mathrm{IgE}$ for Malassezia and C. albicans. There was a correlation between the reduction in the levels of total $\mathrm{IgE}$ and specific $\mathrm{IgE}$ for Malassezia but not between reduction in clinical score and the level of specific IgE for Malassezia. However, for specific $C$. albicans, there was a correlation between a reduction in the specific IgE and total IgE levels and clinical score.

Today oral ketoconazole should not be used for long-term treatment due to the risk of liver toxicity. If ketroconazole is used for more than 14 days, liver enzymes should be monitored before the start of treatment and every 14 days during treatment. The newer azoles, the triazoles fluconazole and itracon- azole, have less risk of side effects; although they are more expensive, they should be the drugs of choice.

In a double-blind placebo-controlled study, Back and Bartosik have treated $29 \mathrm{AD}$ patients with oral ketoconazole at $200 \mathrm{mg}$ once daily or placebo for 3 months (9). In the ketoconazole group, the levels of total $\mathrm{IgE}$ and specific $\operatorname{IgE}$ to both Malassezia and C. albicans decreased significantly. The patients were allowed to use topical corticosteroids during the study period, and the clinical score decreased equally in both groups. However, the improvement was correlated with the use of topical corticosteroids in the control group but not in the ketoconazole group.

Lintu et al. have, in a double-blind, controlled study, treated $80 \mathrm{AD}$ patients with oral ketoconazole at $200 \mathrm{mg}$ or placebo once daily for 30 days (101). Yeast cultures from the skin and pharynx, SPT and specific IgE antibodies for Malassezia, $C$. albicans, and $S$. cerevisiae, the total IgE level in serum, and the clinical severity score was assessed at baseline and after 1 and 3 months. A significant improvement was seen in the clinical score after 30 days of treatment in the ketoconazole group but not in the placebo group. The number of positive Malassezia cultures was also reduced significantly in the ketoconazole group but not in the placebo group. The clinical response was highest in female patients with positive cultures for Malassezia and/or $C$. albicans. In this study there was a slight, but not statistically significant, reduction in the total IgE level after 30 days of treatment with ketoconazole. For all other parameters studied, there were no significant difference between baseline and the 2- or 3-month follow-up visits. This may be due to a shorter treatment period than in earlier trials.

In one study, the positive effect of oral itraconazole in the treatment of patients with AD has been mentioned (66). Topical treatment with bifonazole, in an unknown number of patients, has also been effective in the treatment of AD (144). In an open study, the combination of hydrocortisone and miconazole was effective in the treatment of AD (158). However, in a double-blind controlled study of the effect of hydrocortisone and miconazole compared with hydrocortisone alone in the treatment of $\mathrm{AD}$, no statistically significant difference was found and both treatments were effective (20). Oral treatment may be more effective because it more effectively eradicates the Malassezia yeasts located deep in the follicle.

The number of treatment studies using antifungal therapy is small, and new well conducted, controlled and double-blind trials are needed to confirm if antifungal therapy is beneficial in the treatment of some patients with AD.

\section{Candida}

More than 50 different Candida species have been described (111). Many species have been isolated from human sources, but eight species are dominant these are C. albicans, C. glabrata, C. guilliermondii, C. kefyr, C. krusei, C. parapsilosis, C. tropicalis, and $C$. doblinensis. All the pathogenic Candida species multiply primarily by the production of buds from blastospores. The sizes and shapes of blastospores are sometimes characteristic for a species, but the gross microscopic appearance is more or less similar. The cell wall is multilayered, and the cell membrane is a typical eukaryotic phospholipid bilayer with frequent invaginations. The most commonly encountered pathogenic Candida species usually grow well in aerobic cul- 
tures base on rich or poor nutrient media with a $\mathrm{pH}$ in the range of 2.5 to 7.5 and at a temperature in the range of 20 to $38^{\circ} \mathrm{C}$.

Distribution on normal skin. In persons working in hospitals, in patients with skin diseases, in cancer patients, in patients with immune defects, and in individuals living in a warm and humid climate $C$. albicans may be cultured even from glabrous skin. Other Candida species, e.g., C. parapsilosis, are often cultured from the toe cleft.

Distribution on mucous membranes. Isolation of Candida from the gastrointestinal tract or, in women, the vagina does not automatically imply disease because many healthy persons are colonized with Candida in these areas $(85,111,129)$. An prevalence of 3 to $65 \%$ in asymptomatic persons has been reported (111). Under the influence of various predisposing factors, the prevalence may increase $(111,129)$. The most commonly cultured Candida species is C. albicans, but $C$. glabrata, C. tropicalis, C. parapsilosis, and $C$. krusei may also be found.

The Candida yeasts as pathogens. Infections with Candida occur not only due to the presence of individual or environmental predisposing factors but also due to the virulence of the infecting organism $(111,129)$. Important predisposing factors are human immunodeficiency virus infection, other immunosuppresive disorders, diabetes mellitus, age, pregnancy, hormonal dysfunction, contraceptive pills, and the use of drugs, e.g., oral antibiotics, oral corticosteroids, and immunosuppresive drugs. The presence of skin diseases often predisposes to skin infections with Candida.

Theoretically, Candida may be involved in diseases due to infections or to allergic reactions $(4,111,129)$. In the host defense against Candida, both nonspecific immune mechanisms (e.g., an intact skin barrier or mucous membrane, presence of other microorganisms, polymorphonuclear leukocytes, macrophages, complement, and NK- and/or CD16-positive cells) and specific immune mechanisms (e.g., serum antibodies and cell-mediated immunity) are involved (129). Chronic mucocutaneous candidiasis and systemic candidiasis are both associated with defects in the cell-mediated immune response $(111,129)$. Virulence factors in Candida that are important for an infection are, e.g., adhesion to epithelial or mucosal cells, proteinases, hypha formation, propensity to switch phenotype, and surface hydrophobicity.

Infections by various members of the genus Candida have been reported from almost all anatomical sites $(47,111,112)$; they can be divided into superficial and deep infections. It is not within the scope of this article to give a detailed description of Candida infections. The most commonly seen skin infections are intertrigo, cheilitis, diaper rash, balanitis, paranychia, nail infections (most commonly secondary to paranychia), and folliculitis. Superficial infections on mucous membranes include vaginitis, balanitis (which may involve both skin and mucous membranes), stomatitis, glossitis, and other superficial infections of the gastrointestinal tract. In deep candidiasis, almost all organs may be involved. Many times it is impossible to make a distinction between a primary systemic Candida infection and disseminated candidiasis.

C. albicans contains several antigenic components capable of stimulating immediate hypersensitivity responses. However, although Candida, and especially C. albicans, often is mentioned in relation to various allergic reactions, the majority of these reports are anecdotal and not reports of evidence-based studies. In patients with cutaneous Candida infections, sterile eczematous lesions may occur in other areas of the skin (111). This type of reaction, often called "id" reaction, is also seen in dermatophyte infections, especially tinea pedis due to Trichophyton mentagrophytes (var. interdigitale). Although not evidence based, this type of reaction is called an allergic reaction to fungal material because it disappears when the fungal skin infection heals. The role of an allergic type I reaction to $C$. albicans has also been mentioned for other skin diseases, e.g., chronic urticaria and psoriasis.

Other reports, also of anecdotal origin, in the literature claim that Candida allergy may be a major cause of manifold feelings of lack of well-being, e.g., anxiety, depression, diarrhea, premenstrual tension, poor intellectual function, and many more $(16,111)$. These reactions should be due to the presence of Candida in the gastrointestinal tract or in the blood. These reports are not evidence based, but they may be harmful because they often recommend antimycotic therapy. Non-evidence-based antimycotic therapy should of course be avoided due to the risk of allergic drug reactions, drug interactions, and the risk of development of fungal drug resistance.

\section{Atopic Dermatitis and the Candida yeasts}

Distribution of Candida. There is little information about the colonization of the skin in patients with AD. The available literature describes that Candida species, and especially $C$. albicans, have been cultured more frequently from both normal and lesional skin in patients with $\mathrm{AD}$ than from healthy individuals $(4,111)$. However, there are no reports about any correlation between the presence of $C$. albicans on the skin, the activity of $\mathrm{AD}$, and/or the effects of antifungal therapy.

Candida has been cultured more frequently from the gastrointestinal tract in patients with $\mathrm{AD}$ than in healthy controls $(4,111,129,132)$. In a study by Buslau et al., Candida species were cultured more frequently from feces of patients with AD and those with psoriasis (24); C. albicans was cultured in $90 \%$ of the cases where Candida species were found. The authors cultured yeasts in $70 \%$ of patients with $\mathrm{AD}$ compared to $54 \%$ of healthy controls (24). In a paper by Savolainen et al., $C$. albicans was cultured from the nasopharynx in 31 of 52 patients (59\%) with AD (132). Skin cultures for fungi were negative. A correlation between the severity of $\mathrm{AD}$ and the levels of specific IgE antibodies to $C$. albicans was seen only in AD patients with positive nasopharyngeal cultures.

Immunology. (i) Skin prick test, with C. albicans and other yeasts, for type I hypersensitivity. In a study of 117 adult patients with $\mathrm{AD}, 28$ patients with allergic rhinitis, and 39 healthy controls, $52 \%$ of patients with AD were SPT positive to a C. albicans extract compared to $22 \%$ of patients with allergic rhinitis and $5 \%$ of healthy controls (132). Positive SPTs were more commonly seen in patients with severe AD. Positive SPTs to $S$. cerevisiae, Malassezia, and molds showed a specific association with the presence of specific C. albicans $\operatorname{IgE}$ antibodies.

In a study from Japan, approximately $30 \%$ of patients with AD were SPT positive to a $C$. albicans extract and approximately $40 \%$ of AD patients were SPT positive to a Malassezia 
extract (147). There was no difference between AD patients with or without simultaneous atopic respiratory disease. However, only approximately $10 \%$ of healthy controls were SPT positive. There was a positive correlation between positive results in SPT and specific RAST for both $C$. albicans and Malassezia. In another study by the same group, AD patients who showed larger SPT responses to a $C$. albicans extract tended to display lower lymphocyte proliferative responses (148). In a study by Morita et al. (106), the role of $C$. albicans in $\mathrm{AD}$ was evaluated and various immunological parameters were compared in patients with AD (37), patients with allergic rhinitis (23), and nonatopic subjects (42). The SPT response was significantly larger in the AD group than in the non-AD group.

Nissen et al. prick tested 15 patients with the head and neck distribution of $\mathrm{AD}$ or secondary infected $\mathrm{AD}$ with both culture filtrates and cellular extracts of $C$. albicans and Malassezia (109). Culture filtrates contain metabolites and cell wall components, whereas cellular extracts contain predominantly cell walls and probably fewer metabolites. Of 15 patients, $4(27 \%)$ were SPT positive to C. albicans cellular extract and 2 or $13 \%$ were SPT positive to the culture filtrate. Of 15 patients, 9 $(60 \%)$ were SPT positive to a commercially available Malassezia extract. The authors also included the leukocyte histamine release test in this study. The results were more or less comparable to the SPT results.

Kortekangas-Savolainen et al. have studied the SPT results to an extract of $S$. cerevisiae in 226 patients with AD, 50 patients with allergic rhinitis and/or asthma, and 173 nonatopic controls (81). A positive SPT result was seen in $94 \%$ of patients with severe $\mathrm{AD}, 76 \%$ of patients with moderate $\mathrm{AD}$, and $25 \%$ of patients with mild AD. Patients with allergic rhinitis and/or asthma and nonatopic controls showed positive results in 8 and $2 \%$ of tests, respectively. A significant correlation was found between total serum IgE levels and SPT results. There was also a parallel between SPT result with Malassezia and C. albicans, indicating a cross-reactivity.

Positive SPT results to Candida were found in 22 to $94 \%$ of $\mathrm{AD}$ patients were lower in healthy controls. The largest number of positive reactions was seen in patients with severe AD. Previous studies have found positive SPT reactions to C. albicans in 52\% (132), 25 to 94\% (81), 30\% (147), and 27\% (109) of patients with AD.

(ii) Specific IgE antibodies to $C$. albicans and other yeasts. One of the first reports of production of specific $\mathrm{IgE}$ antibodies against C. albicans was presented by Okudaira et al. in 1983 (113). They found the production of specific C. albicans IgE antibodies in patients with $\mathrm{AD}$ and/or asthma but not in controls.

In the above-mentioned paper by Savolainen et al., the severity of $\mathrm{AD}$ was associated with the production of $C$. albicansspecific IgE antibodies (132). In patients with the head and neck distribution of $\mathrm{AD}$, there was a significant correlation between specific $\mathrm{IgE}$ antibodies and severity of $\mathrm{AD}$ only in patients with gastrointestinal growth of $C$. albicans. This pattern was also the same for $\mathrm{AD}$ in general but not for $\mathrm{AD}$ located only to the body or extremities. The specific summarized IgE staining responses to all allergens (both mannan and proteins) in immunoblot analyses, as well as the total serum IgE levels, were highest in patients with severe AD.
In a study by Tanaka et al., the production of specific IgE antibodies against $C$. albicans and Malassezia was significantly higher in patients with $\mathrm{AD}$ than in healthy controls, and the levels were also higher in patients with $\mathrm{AD}$ (49 patients) alone than in patients with both $\mathrm{AD}$ and allergic respiratory disease (48 patients) (147). In another study, Tanaka et al. found that $\mathrm{AD}$ patients with higher total IgE levels in serum as well as higher specific C. albicans IgE antibody levels tended to display lower lymphocyte proliferative responses than did patients with lower levels, although the correlation was not statistically significant (148).

Back et al. found specific IgE antibodies to C. albicans in 21 of 69 patients with $\mathrm{AD}(33 \%)$ but none in patients with seborrheic dermatitis or in healthy controls (8). The correlation between specific IgE antibodies to $C$. albicans and Malassezia was strong: 20 of 28 patients with specific Malassezia IgE antibodies had IgE antibodies to $C$. albicans, and 20 of 21 patients with specific $C$. albicans $\mathrm{IgE}$ antibodies also had $\mathrm{IgE}$ antibodies to Malassezia. There was also a correlation between the total IgE level and the levels of specific IgE antibodies to both $C$. albicans and Malassezia

Matsumura et al. studied total $\mathrm{IgE}$ and production of specific IgE antibodies to $C$. albicans in 46 patients with $\mathrm{AD}, 41$ patients with allergic respiratory disease, and 42 healthy controls (102). Both patients with $\mathrm{AD}$ and those with allergic respiratory disease showed a significantly higher total $\mathrm{IgE}$ than did controls. However, specific C. albicans IgE antibody levels were significantly higher in patients with $\mathrm{AD}$ than in patients with allergic respiratory disease. Patients with $\mathrm{AD}$ also reacted to a larger number of allergens than did those with allergic respiratory disease.

Doekes et al. found a highly significant correlation between levels of anti-Malassezia $\mathrm{IgE}$ and $\mathrm{IgE}$ reacting with extracts of C. albicans (30). Of 128 sera from AD patients, 34 sera reacted positively with both yeast extracts, 38 reacted with Malassezia but not with $C$. albicans extract, and only 1 of the 56 antiMalassezia-negative sera showed a very week reaction with $C$. albicans. The correlation was due to a marked cross-reactivity, as shown by inhibition enzyme-linked immunosorbent assay. However, Malassezia allergens were more potent inhibitors than were the corresponding $C$. albicans components, suggesting than the $\mathrm{IgE}$ antibodies in $\mathrm{AD}$ result from sensitization to Malassezia and then cross-react with $C$. albicans.

In a report by Nermes et al., a RAST test for determination of $\mathrm{IgE}$ antibodies to C. albicans mannan was described (108). Of 78 patients with $\mathrm{AD}, 53(68 \%)$ showed elevated levels compared to healthy controls, and there was a significant correlation with the severity of $\mathrm{AD}$. Of 30 patients with asthma 16 $(53 \%)$ had elevated IgE mannan C. albicans antibody levels in serum. However, 12 of these 16 patients with a positive result also had $\mathrm{AD}$. Of 32 patients with allergic rhinitis but without AD, $12(38 \%)$ had elevated mannan IgE antibody titers. This RAST method is a sensitive assay for determination of polysaccharide-specific $\operatorname{IgE} C$. albicans antibodies in patients with $\mathrm{AD}$.

As part of a more extensive immunological study of patients with $\mathrm{AD}$, Kawamura et al. measured total $\operatorname{IgE}$ and specific $C$. albicans IgE antibody levels in serum in 15 adult patients with $\mathrm{AD}$ (73). All patients had elevated total IgE levels, and 12 of 14 patients showed elevated specific $C$. albicans IgE antibody levels. 
Savolainen et al. studied the presence of IgE-, IgA-, and IgG-specific yeast antibodies (total) and yeast mannan-specific $\mathrm{IgE}, \operatorname{IgA}$, and $\mathrm{IgG}$ antibodies in patients with atopic diseases (133). Of 20 patients, 14 were C. albicans SPT positive, 1 was C. utilis SPT positive, and 1 was Rhodotorula rubra SPT positive. A total of 12 patients with $\mathrm{AD}$ and 2 with rhinitis had specific $C$. albicans IgE antibodies in immunoblot analyses, and 10 (9 with AD and 1 with rhinitis) of 14 tested patients had $C$. albicans-specific mannan $\mathrm{IgE}$ antibodies. Nine patients had specific IgE antibodies to $C$. utilis, 8 patients had specific IgE antibodies to $R$. rubra, 4 patients had specific IgE antibodies to $S$. serevisiae, and 4 patients had specific $\operatorname{IgE}$ antibodies to Cryptococcus albidus. IgA-specific antibodies were detected in 25 to $85 \%$ of the patients; the highest level was for C. albicans, and the lowest level was for $R$. rubra. IgA mannan-specific antibodies were detected in 18 to $100 \%$; the highest level was for C. albicans and the lowest level was for Cryptococcus albidus. IgG-specific antibodies were detected in 20 to $95 \%$; the highest level was for $S$. cerevisiae, and the lowest level was for C. utilis. IgG mannan-specific antibodies were detected in 74 to $100 \%$; the highest level was for R. rubra, and the lowest level was for $S$. cerevisiae. Cross-reactivity between $C$. albicans and the other yeasts may probably explain several of the positive reactions to yeasts other than $C$. albicans.

In a study by Nissen et al., IgE-specific antibodies to $C$. albicans and Malassezia were studied using immunoblotting (109). Of AD patients, 93\% had specific Malassezia IgE antibodies, $47 \%$ had specific IgE antibodies to a $C$. albicans cellular extract, and $60 \%$ had specific IgE antibodies to a culture filtrate extract of $C$. albicans. Savolainen et al. studied specific $\mathrm{IgE}$ and $\mathrm{IgG}$ antibodies to a protein and mannan antigen from C. albicans in sera from 10 patients with $\mathrm{AD}$ and 7 healthy controls (134). Levels of both mannan- and protein-specific $\mathrm{IgE}$ antibodies were elevated in $\mathrm{AD}$ patients compared to controls. The anti-mannan $\mathrm{IgG}$ responses were higher than the anti-protein $\mathrm{IgG}$ responses. However, no significant differences between $\mathrm{AD}$ patients and controls were seen. Morita et al. found that the total $\operatorname{IgE}$ level was significantly higher in patients with $\mathrm{AD}$ (37 patients) than in both patients with allergic rhinitis (23 patients) and healthy controls (42 subjects) (106). C. albicans-specific $\mathrm{IgE}$ was found in $85 \%$ of $\mathrm{AD}$ patients compared to only $9 \%$ of patients with allergic rhinitis and $5 \%$ of healthy controls.

Scalabrin et al. investigated specific IgE responses to various fungi and house dust mites in 73 patients with $\mathrm{AD}$ (including 16 children), 156 patients ( 54 children) with asthma, and 212 non-asthmatic patients (102 children) (136). Patients with AD had significantly higher total IgE levels than did those in the other two groups. Specific IgE antibodies to both $C$. albicans and Malassezia were detected in 75 and 54\%, respectively. However, for Malassezia, significantly larger numbers of adult patients $(65 \%)$ than of children $(13 \%)$ had specific IgE serum antibodies. There was also a statistically significant correlation between the total serum IgE level and the level of specific IgE to both $C$. albicans and Malassezia as well as between specific C. albicans and Malassezia IgE antibodies, indicating a crossreaction. Adachi et al. found that the percentage of $\mathrm{AD}$ patients with specific $C$. albicans IgE antibodies was significantly higher for patients with severe symptoms and high total serum IgE levels (2). This was also found in patients with specific
TABLE 3. Specific IgE serum antibodies to $C$. albicans in patients with AD

\begin{tabular}{|c|c|c|}
\hline Study & \multicolumn{2}{|c|}{$\begin{array}{l}\% \text { of } \mathrm{AD} \text { patients } \\
\text { with specific IgE } \\
\text { C. albicans antibodies }\end{array}$} \\
\hline Savolainen et al., 1993 (132 & ............... & 60 \\
\hline Doekes et al., 1993 (30) ...... & ................ & 28 \\
\hline Nermes et al., 1994 (108)... & ............. & 68 \\
\hline Tanaka et al., 1994 (147) ... & ............ & 41 \\
\hline Back et al., 1995 (8) ............... & .............. & 33 \\
\hline Matsumera et al., 1997 (103 & ................ & 25 \\
\hline Kawamura et al., 1998 (73) & ................. & 88 \\
\hline Savolainen et al. 1998 (133) & ................ & 80 \\
\hline Nissen et al., 1998 (109)...... & ................. & 47 \\
\hline Morita et al., 1999 (106) ..... & ............... & 85 \\
\hline Scalabrin et al., 1999 & ............... & 75 \\
\hline Adachi et al., 1999 (2) ......... & ............... & 87 \\
\hline
\end{tabular}

Malassezia IgE antibodies. Patients with the head and neck distribution of $\mathrm{AD}$ had higher specific $\operatorname{IgE}$ titers to both $C$. albicans and Malassezia. Kimura et al. found high specific $C$. albicans IgE antibody levels in patients with $\mathrm{AD}$ (78); specific $\mathrm{IgE}$ antibodies were found in $87 \%$ of patients with $\mathrm{AD}$ compared to only $15 \%$ of patients with asthma.

In a study by Broberg et al. of children with $\mathrm{AD}$, specific $C$. albicans IgE antibodies were found in only $16 \%$ (9 of 57) (19). Lindgren et al. measured the levels of total $\mathrm{IgE}$ and specific $\mathrm{IgE}$ antibodies to a variety of external allergens in 119 children with AD (97). Of these children, $47 \%$ had specific $C$. albicans IgE antibodies and 34\% had specific Malassezia IgE antibodies. RAST positivity to all allergens increased with age. However, this was most pronounced for Malassezia, where $43 \%$ of 10 -year-old children had specific Malassezia IgE antibodies. The RAST-positive children generally had worse AD than did the RAST-negative children. Children who were RAST positive to $C$. albicans and/or Malassezia not only had a more severe AD than did RAST-negative children but also more often had AD with a head and neck distribution.

The frequency of specific serum Candida $\mathrm{IgE}$ varied from study to study. In general, the number of patients with specific antibodies was larger for adults than for children, for patients with severe $\mathrm{AD}$ than for those with mild $\mathrm{AD}$, and for patients with a high total IgE level. Another explanation for the variation in the results obtained in various studies is the difference in the antigen preparation. Table 3 summarizes the specific IgE antibody responses found in the literature.

Nermes et al. have studied the antibody response to $C$. albicans mannan in children younger than 5 years with and without $\mathrm{AD}$ (108). There was no difference in the production of C. albicans IgG- and IgA-specific antibodies between the two groups. IgM anti-mannan levels were higher in 5-year-old children with AD. The authors concluded that children are not more susceptible to bacterial infections on the basis of poorer ability to produce antibodies to polysaccharide antigens.

(iii) Characterization of antigens. Several of the papers dealing with characterization of $C$. albicans antigens have already been mentioned in the section on Malassezia antigens due to the cross-reactivity between these two yeasts.

Ishiguro et al. have identified various antigens from $C$. albicans that reacted with $\mathrm{IgE}$ antibodies from sera of 57 patients with allergic diseases (64). The 175-, 125-, 46-, 43-, and 37-kDa 
antigenic components reacted most frequently. The 46-, 43-, and $37-\mathrm{kDa}$ antigens were recovered in cytoplasmic fractions and had homology to the $S$. cerevisiae glycolytic enzymes enolase, phosphoglycerate kinase, and aldolase, respectively. The $175-$ and $125-\mathrm{kDa}$ antigens were not recovered in any fraction. This result suggests that the levels of $\operatorname{IgE}$ antibodies against only small parts of their epitopes are elevated in the allergic patients and that, e.g., enolase may be a major immunodominant protein in both allergies and fungal infections.

Savolainen et al. found the most dominant protein allergens from $C$. albicans to be $27-$ and 46-kDa proteins (132). However, these allergens changed when the same patients were studied 5 years later and the $\operatorname{IgE}$ responses were found to be directed mostly against allergen bands with molecular masses of 34, 29, 20, and $13 \mathrm{kDa}$. IgA and IgG responses were directed mainly against the polysaccharide mannan.

Kortekangas-Savolainen et al. have tried to characterize the $\mathrm{IgE}$ binding components of $S$. cerevisiae (81). The found that the most frequent staining was found with a $48-\mathrm{kDa}$ band. When the staining pattern of the 48-kDa band, a 45-kDa band, and mannan was compared with $C$. albicans allergens or purified $S$. serevisiae enolase, a simultaneous binding was seen with the $48-\mathrm{kDa}$ band of $S$. cerevisiae and the $46-\mathrm{kDa}$ band of $C$. albicans and enolase whereas the $45-\mathrm{kDa}$ band was not associated with the $46-\mathrm{kDa}$ band of $C$. albicans or the purified enolase. Nermes et al. analyzed cross-reactivity between $C$. albicans and $S$. cerevisiae mannans (108). IgE binding to all three studied mannans from both yeasts was seen simultaneously. However, the strongest response was seen to C. albicans mannan. These results indicate that in AD patients, simultaneous $\mathrm{IgE}$ responses to various yeast polysaccharides occur, that the major sensitizer is $C$. albicans, and that the $S$. cerevisiae mannan is cross-reacting.

Savolainen et al. studied the major protein profiles of extracts from C. albicans, C. utilis, R. rubra, and Cryptococcus albidus (133). The greatest similarity in the protein profiles was seen between $C$. albicans and $C$. utilis, which both showed a dominant protein staining of $46 \mathrm{kDa}$. In IgE immunoblotting, prominent IgE binding to the $46-\mathrm{kDa}$ band was seen in one serum sample not only to $C$. albicans and $C$. utilis but also to $S$. cerevisiae and to a lesser extent to the corresponding weak bands of $R$. rubra and Cryptococcus albidus. The IgE immunoblotting also revealed the largest number of $\mathrm{IgE}$ binding bands in $C$. albicans followed by $C$. utilis, $S$. cerevisiae, $R$. rubra, and Cryptococcus albidus. When cross-reactivity was studied with immunoblotting inhibition, the C. albicans inhibition of $C$. utilis reached $80 \%$ inhibition. The enolase staining was almost as strongly inhibited with $C$. albicans as was the autoinhibition. $S$. cerevisiae enolase inhibited C. albicans staining to $55 \%$ and $C$. utilis staining to only $15 \%$, while the same concentration gave an enolase autoinhibition of $98 \%$. An important IgG and IgA response was seen with high-molecular-weight mannan-like components.

(iv) Cellular and cytokine responses. Several papers dealing with cellular and cytokine responses have already been mentioned in the Malassezia section. The delayed-type hypersensitivity response to C. albicans was found in several studies to be different from the result seen with Malassezia and other environmental allergens.

Using the chamber-scarification patch test technique, 97 pa- tients with $\mathrm{AD}$ were investigated for delayed-type hypersensitivity against extracts from C. albicans, Malassezia, and other environmental allergens (147). Healthy controls had a higher incidence of positive patch test results ( $86 \%$ positive) against C. albicans than did patients with AD (49\%). For the other environmental allergens tested, including Malassezia (approximately $10 \%$ positive), the incidence of positive results in patients with $\mathrm{AD}$ was equal to or higher than the reaction seen in healthy controls. A negative correlation between the patch test result for $C$. albicans and both total $\operatorname{IgE}$ and specific RAST to C. albicans was found in patients with AD. The authors conclude that the persistent exposure to $C$. albicans allergen in patients with $\mathrm{AD}$ leads to the development of immediate hypersensitivity, with a subsequent decrease or total loss of delayed-type hypersensitivity to C. albicans allergen. This is in parallel with the results of experimental dermatophytosis experiments in patients with AD (68). The persistent carriage of C. albicans in the oral cavity and intestine may induce a Th2type T-cell response that facilitates the $\operatorname{IgE}$ response on the one hand but reduces the delayed-type hypersensitivity on the other (147).

In another study by the same group, the incidence of positive patch test results in respons to a $C$. albicans allergen was again significantly lower in patients with $\mathrm{AD}$ than in healthy controls (148). The results of a lymphocyte stimulation test with a $C$. albicans allergen, using PBMC from AD patients, gave a significant lower stimulation index than for healthy controls. The results with Staphylococus enterotoxin A and B were similar for $\mathrm{AD}$ patients and healthy controls.

Matsumura et al. performed patch test (scarification) experiments using various environmental allergens in 46 patients with $\mathrm{AD}$ (without any respiratory allergy), in 41 patients with allergic respiratory disease but without $\mathrm{AD}$, and in 42 healthy controls (103). AD patients showed a significantly lower incidence of positive responses to C. albicans (34\%) than did both patients with allergic respiratory disease $(90 \%)$ and healthy controls $(84 \%)$. When the patch test results were compared to specific RAST results the percentage of those with positive RAST results and negative patch test results was higher in the AD group, while the percentage of those with negative RAST results and positive patch test results was strikingly higher in the group with allergic respiratory disease.

In a study by Kawamura et al., PBMC from both patients with $\mathrm{AD}$ and healthy controls were incubated with a crude extract of $C$. albicans (73). PBMC from both AD patients and healthy controls showed a significant increase in proliferation. However, PBMC from healthy controls showed a significantly higher stimulation index than did PBMC from AD patients. When PBMC stimulated with $C$. albicans were costimulated with monoclonal antibodies to CD40-, CD54-, CD80-, or CD86-positive cells, the proliferation was suppressed in a significantly larger number of subjects with anti-CD54 than with any of the other antibodies. This effect of anti-CD54 was seen in both $\mathrm{AD}$ patients and healthy controls.

Kimura et al. have studied the production of IFN- $\gamma$ and IL-5 by PBMC after stimulation with an extract of $C$. albicans in patients with $\mathrm{AD}$, patients with bronchial asthma and healthy controls (77). The amount of IFN- $\gamma$ produced was significantly smaller in AD patients than in both patients with bronchial asthma and healthy controls. The production of IL-5 was again 
TABLE 4. Treatment of AD patients with antifungal drugs

\begin{tabular}{llll}
\hline \multicolumn{1}{c}{ Study } & \multicolumn{1}{c}{ Treatment } & \multicolumn{1}{c}{ Design } & \multicolumn{1}{c}{ Results } \\
\hline Clemensen and Hjorth 1983, (26) & Oral ketoconazole & Double-blind crossover & Ketoconazole $>$ placebo \\
Back et al., 1995 (8) & Oral ketoconazole & Open & Ketoconazole $>$ placebo \\
Morita et al., 1999 (106) & Oral ketoconazole or fluconazole & Open & Ketoconazole $=$ fluconazole \\
Back et al., 2001 (9) & Oral ketoconazole & Double blind & Ketoconazole $=$ placebo \\
Lintu et al., 2001 (101) & Oral ketoconazole & Double blind & Ketoconazole $>$ placebo \\
White et al., 1983 (158) & Topical hydrocortisone + miconazole & Open & Active $>$ placebo \\
Broberg et al., 1995 (20) & Topical hydrocortisone + miconazole & Double blind & Active $=$ placebo \\
\hline
\end{tabular}

significantly lower in patients with $\mathrm{AD}$ than in patients with bronchial asthma but comparable to the production in healthy controls. The production of both INF- $\gamma$ and IL-5 was significantly lower in patients with severe AD than in to patients with mild to moderate AD. Therefore, decreased IFN- $\gamma$ and IL-5 production seems not to be an accessory phenomenon but appears to be related to an essential immunological abnormality which results in AD. The authors conclude that it remains to be elucidated whether the decreased cytokine production by PBMC, after stimulation with $C$. albicans, from patients with $\mathrm{AD}$ is due to decreased cytokine production per cell or to a decrease in the number of cytokine-producing cells in PBMC.

These results obtained by Kawamura et al. (77) are in conflict with results obtained by Savolainen et al. (134). They found that both a mannan and a protein extract from C. albicans induced an higher proliferative response in patients with $\mathrm{AD}$ than in healthy controls. In general, mannan was a clearly stronger inducer of lymphoproliferation and cytokines. Mannan, but not protein, induced higher IL-2 response in AD patients than in healthy controls. Both mannan and protein induced the same level of IL-4 response in AD patients and healthy controls. Mannan induced a higher IFN- $\gamma$ production in $\mathrm{AD}$ patients than in healthy controls. In $\mathrm{AD}$ patients there was a correlation for both protein and mannan $C$. albicans extract between IL-2, IL-4, and IFN- $\gamma$ production, total serum IgE level, and specific C. albicans IgE level.

However, Kimura et al. found again, in a study performed in 2000 , that the production of IFN- $\gamma$ in patients with AD was significantly lower than that in both patients with bronchial asthma and healthy controls (78). They found no significant difference in the production of IL-4 among these three groups. In contrast to Savolainen et al. (134) they found a significant negative correlation between specific serum $C$. albicans $\mathrm{IgE}$ and IFN- $\gamma$ production by $C$. albicans-stimulated PBMC.

In a recently published study by Savolainen et al., the proliferative response by PBMC, after stimulation with both $C$. albicans and Malassezia extracts, was significantly higher in AD patients than in healthy controls (135). For C. albicans, IL-5 production and IFN- $\gamma$ production was significantly higher in $\mathrm{AD}$ patients than in healthy controls. C. albicans-induced IFN- $\gamma$ production was significantly higher than for Malassezia. Malassezia-induced IL-4 production was significantly higher than for C. albicans. Total IgE and PHA-induced IL-2 and IL-4 levels in serum were elevated. A network of correlations was seen between the total $\mathrm{IgE}$ level in serum and the yeast-specific IgE level, Malassezia-specific proliferation, PHA-induced IL-2 and IL-4 levels, and the C. albicans-induced IL-5 level, suggesting that these are associated with $\mathrm{AD}$. According to the authors, hypersensitivity to yeasts is an important pathogenic factor in some cases of $\mathrm{AD}$. Both C. albicans and Malassezia can induce IgE, lymphoproliferation, IL-2, IL-4, IL-5, and IFN- $\gamma$ responses. However, according to the authors, Malassezia is a stronger inducer of Th2-type response and C. albicans is a stronger inducer of Th1-type responses.

There are several explanations of the differences obtained in different studies. Kimura et al. studied children, and Savolainen et al. studied mainly adults. Differences in the preparation of extracts, the length of the culture period, and the methods used for the experiments are also important factors. The lymphocyte stimulation responses and cytokine responses found in the literature can be summarized as follows: Kawamura et al. (73) found increased lymphocyte stimulation but less than in healthy controls; Kimural et al. in 1999 (76) found decreased production of IL-5 and IFN- $\gamma$ and in 2000 (78) found decreased production of IFN- $\gamma$; Sarolainer et al. in 1999 (134) found increased production of IL-2 and IFN- $\gamma$ and in 2001 (140) found increased production of IL-5, IL-2, and IFN- $\gamma$.

Treatment. Several studies have already been mentioned in the section dealing with Malassezia yeasts and treatment of AD $(8,9,101)$.

In the above-mentioned study by Morita et al., five patients with AD were treated orally once daily with $50 \mathrm{mg}$ of ketoconazole and five patients with $\mathrm{AD}$ were treated orally once daily with $50 \mathrm{mg}$ of fluconazole for 3 months (106). In both treatment groups, four patients were evaluated as improved after 3 months of treatment, and C. albicans-specific IgE levels in serum were significantly decreased in both groups.

In a study by Adachi et al. (2), the effect of oral antifungal treatment was evaluated in 140 patients with treatment refractory $\mathrm{AD}$ and with a positive specific RAST result to $C$. albicans. According to the authors, good or excellent results were obtained in $60 \%$ of patients receiving fluconazole, $35 \%$ receiving itraconazole, $31 \%$ receiving oral amphotericin $\mathrm{B}$, and $28 \%$ receiving nystatin. The number in each group, the dosage, and the length of treatment are not mentioned in the English abstract of this Japanese paper. That oral amphotericin B and nystatin both work indicate that $C$. albicans present in the gastrointestinal tract may be important as an allergen in AD.

Although some studies may indicate that antifungal treatment of both Malassezia and Candida may be effective in the treatment of some patients with $\mathrm{AD}$, we need further controlled studies to really prove this. Table 4 summarizes the results of treatment studies mentioned in the literature.

\section{Atopic Dermatitis, Dermatophytes, and Other Hyphomycetes}

There are conflicting data in the literature about the association of $\mathrm{AD}$ with chronic dermatophyte infections $(68,143)$. 
However, if a patient with $\mathrm{AD}$ develops a chronic dermatophyte infection, it is often more severe and more difficult to eradicate. The first extensive report about a link between AD and chronic dermatophyte infections was presented by Jones et al. (67). They found that $14(40 \%)$ of 25 patients with chronic dermatophyte infections were atopic (AD, asthma, hay fever, or all three). A comparison of the frequency of chronic dermatophyte infection showed that $41 \%$ (14 of 34) in the atopic group had chronic dermatophyte infections compared to only $14 \%$ (21 of 146) in the nonatopic group. They also found that there was no correlation between chronic dermatophyte infection and any clinical condition except atopy. Of the $14 \mathrm{AD}$ patients with chronic dermatophyte infections, 11 (79\%) manifested immediate sensitivity to Trichophyton.

However, the reason for the failure of immunity in persistent dermatophyte infections and its relationship to chronicity are still not well understood. There is an association between the presence of atopy and chronic dermatophytosis. A high proportion of those with persistent disease had atopic diseases (most commonly asthma or hay fever) as well as immediatetype hypersensitivity and raised total $\operatorname{IgE}$ levels $(57,68)$. It has been suggested that modulation of T-lymphocyte activity either locally (in the skin) or systemically may be responsible. Possible mechanisms include activation of a Th2 pathway, which might explain the spectrum of antibody responses. It has also been found that dermatophyte antigens, including those that contain mannose residues, can reversibly suppress lymphocyte proliferation but not the expression of human leukocyte antigen (HLA-DK) $(71,104)$. Patients with persistent infection have detectable levels of circulating antigen. Both are possible factors in the regulation of immunity in dermatophytosis.

In a study by Rajka and Barlinn, patients with $\mathrm{AD}$ and chronic dermatophyte infections showed not only positive immediate reactions to Trichophyton but also to Penicillium and Cladosporium (117). Even patients with AD who showed no sign of dermatophyte infections had this cross-reactivity. However, this was absent in nonatopic patients with chronic dermatophyte infections, and healthy controls were negative to all the three extracts. These findings indicate that immediate reactivity to Trichophyton in AD patients is not necessarily a sign of contact with dermatophytes, but a cross-response based on mold reactivity.

Patients with dermatophytosis are usually otherwise healthy. However, chronic and extensive infections have been reported to be more common in patients with immunodeficiency (68). In addition, there is an increased incidence of atopy in those with chronic infections, suggesting that host factors may well determine the clinical course.

Dermatophytes may also have an impact on the severity of atopy, especially asthma (163). Platts-Mills et al. reported on a patient with severe asthma, tinea pedis, and tinea cruris who showed positive results of immediate skin test and RAST to Trichophyton (115). When the patient was treated with an effective antifungal drug, his asthma improved significantly. Ward et al. have reported 12 patients with allergic respiratory diseases with positive immediate reactions to Trichophyton, whose disease became worse when they were challenged with Trichophyton antigen (155). Eight of these patients improved when treated with specific systemic antifungal therapy.

Even AD patients with dermatophyte infections may show improvement of their $\mathrm{AD}$ when treated with specific antifungal therapy (163). Wilson et al. have described a patient with tinea unguium, recalcitrant $\mathrm{AD}$, and specific IgE Trichophyton serum antibody who showed improvement of her $\mathrm{AD}$ when treated with oral antifungal treatment. Klein et al. have also described a patient with AD and tinea pedis and tinea unguium culture positive for T. rubrum (79). The patient showed improvement of her AD when treated with oral ketoconazole for her tinea infection.

Scalabrin et al. have studied the presence of total $\operatorname{IgE}$ and specific IgE to various fungi in AD patients (136). The majority of $\mathrm{AD}$ patients had both elevated total $\mathrm{IgE}$ and specific $\mathrm{IgE}$ antibodies directed against Aspergillus fumigatus and A. alternata (fungi that are characteristically inhaled) as well as against C. albicans, M. furfur, and T. rubrum (fungi that colonize the skin or mucous membranes). There were extensive correlations among specific IgE for each of the fungi. The authors conclude that fungi may be important allergens in several patients with $\mathrm{AD}$ and that antifungal therapy may improve $\mathrm{AD}$ in many patients.

Lindgren et al. found that $18 \%$ of children with $\mathrm{AD}$ had $\operatorname{IgE}$ antibodies to Trichophyton (97). These patients also had specific antibodies to other fungi, house dust mites, and other environmental allergens. Seven children with positive RAST results to both $T$. rubrum, Malassezia, and $C$. albicans had severe $\mathrm{AD}$.

\section{CONCLUSION}

Do yeasts and other fungi play any role in AD? As shown in this review, there are conflicting data in the literature. It is important to remember that fungi are not the causative agents of AD. However, in some patients especially in adult patients who do not respond to traditional treatment, Malassezia and Candida may play a role. Although some studies indicate that antifungal treatment of both Malassezia and Candida may be effective in the treatment of some patients with AD, we need new, well-conducted, double-blind controlled studies to really prove this. It is also important to remember that a possible allergic or nonimmunogenic role of fungi is just an aggravating factor in $\mathrm{AD}$ and that traditional treatment with emollients and anti-inflammatory agents is still necessary. In the literature, conflicting results are presented for both immediate hypersensitivity (SPT and IgE), delayed hypersensitivity (APT), lymphocyte stimulation assays, and IL assays. There are several explanations for this: adult patients compared to children, the severity of $\mathrm{AD}$, the presence of other atopic manifestations, differences in the preparation of extracts, the length of the culture period used, and the method of the assay.

\section{REFERENCES}

1. Abeck, D., and M. Mempel. 1998. Staphylococcus aureus colonization in atopic dermatitis and its therapeutic implications. Br. J. Dermatol. 139(Suppl. 53):13-16.

2. Adachi, A., T. Horikawa, M. Itchihashi, T. Takashima, and A. Komura. 1999. Role of Candida allergen in atopic dermatitis and efficacy of oral therapy with various antifungal agents. Arerugi 48:719-725. (In Japanese, English abstract.)

3. Akiyama, H., J. Tada, Y. Toi, H. Kanzaki, and J. Arata. 1997. Changes in Staphylococcus aureus density and lesion severity after topical application of povidone-iodine in cases of atopic dermatitis. J. Dermatol. Soc. 16:23-30.

4. Arzumanyan, V. G., O. O. Magarshak, and B. F Semenov. 2000. Yeast fungi in patients with allergic diseases: species variety and sensitivity to antifungal drugs. Bull. Soc Exp. Biol. Med. 129:601-604.

5. Arzumanian, V. G. 2001. The yeast Malassezia on the skin of healthy 
individuals and patients with atopic dermatitis. Vestn. Ross. Akad. Med. Nauk. 2:29-31. (In Russian, English abstract.)

6. Ashbee, H. R., E. ingham, K. T. Holland, and W. J. Cunlife. 1994. Cellmediated immune responses to Malassezia furfur serovars A, B and C in patients with pityriasis versicolor, seborrhoeic dermatitis and controls. Exp. Dermatol. 3:106-112

7. Back, O., J. Faergemann, and R. Hörnqvist. 1985. Pityrosporum folliculitis: a common disease of the young and middler aged. J. Am. Acad. Dermatol. 12:56-61.

8. Back, O., A. Scheynius, and S. G. O. Johansson. 1995. Ketoconazole in atopic dermatitis: therapeutic response is correlated with decrease in serum IgE. Arch. Dermatol. Res. 287:448-451.

9. Back, O., and J. Bartosik. 2001. Systemic ketoconazole for yeast allergic patients with atopic dermatitis. J. Eur. Acad. Dermatol. Venereol. 15:34 38.

10. Bailon, H. 1889. Traité de botanique médicale cryptogamique, p. 234-239. Octave Douin, Paris, France.

11. Banfield, C. C., R. E. Callard, and J. L. Harper. 2001. The role of cutaneous dendritic cells in the immunopathogenesis of atopic dermatitis. Br. J. Dermatol. 144:940-946.

12. Barnett, J. A., R. W. Payne, and D. Yarrow. 1990. Yeasts: characteristics and identification, 2nd ed., p. 22-23. Cambridge University Press, Cambridge, United Kingdom.

13. Bergbrant, I. M., and J. Faergemann. 1988. Variations of Pityrosporum orbiculare in middle-aged and elderly individuals. Acta Dermato-Venereol. 68:537-540

14. Bergbrant, I. M., and J. Faergemann. 1990. The role of Pityrosporum ovale in seborrhoeic dermatitis. Semin. Dermatol. 9:262-268.

15. Bergbrant, I. M., and A. Broberg. 1994. Pityrosporum ovale culture from the forehead of healthy children. Acta Dermato-Venereol. 74:260-261.

16. Bergkhout, C. M. 1923. De schimmelgeschlachten Monilia, Oidium, Oospora, en Torula. Ph.D dissertation. University of Utrecht, Utrecht, The Netherlands.

17. Bingham, E. A. 2000. Guidelines to management of atopic dermatitis, p 215-230. In J. Harper, A. Oranje, and N. Prose (ed.), Textbook of pediatric dermatology. Blackwell Science, Oxford, United Kingdom.

18. Brehler, R. B. S., and T. A. Luger. 2001. Atopic dermatitis: the role of Pityrosporum ovale. J. Eur. Acad. Dermatol. Venereol. 15:5-6.

19. Broberg, A., J. Faergemann, S. Johansson, S. G. O. Johansson, and I.-L. Strannegard. 1992. Pityrosporum ovale and atopic dermatitis in children and young adults. Acta Dermato-Venereol. 72:187-192

20. Broberg, A., and J. Faergemann. 1995. Topical antimycotic treatment of atopic dermatitis in the head/neck area. Acta Dermato-Venereol. 75:46-49.

21. Brook, I. 1996. Microbiology of infected atopic dermatitis. Int. J. Dermatol. 35:791-793.

22. Bruijnzeel-Koomen, C. A. F. M., D. F. Van Wichen, J. Toonstra, L. Berrens, and P. L. B. Bruynzeel. 1986. The presence of IgE molecules on epidermal Langerhans cells in patients with atopic dermatitis. Arch. Dermatol. Res. 278:199-205.

23. Buentke, E., S. Zargari, L. C. Heffler, J. Avila-Carino, J. Savolainen, and A. Scheynius. 2000. Uptake of the yeast Malassezia furfur and its allergenic components by human immature CD1a + dendritic cells. Clin. Exp. Allergy 30:1759-1770.

24. Buslau, M., I. Menzel, and H. Holzmann. 1988. Fungal flora of human faeces in psoriasis and atopic dermatitis. Mycoses 33:90-94.

25. Castellani, A., and A. J. Chalmers. 1913. Manual of tropical medicine. Ballière et Cox, London, United Kingdom.

26. Clemmensen, O. J., and N. Hjorth. 1983. Treatment of atopic dermatitis of the head and neck with ketoconazole in patients with type I sensitivity to Pityrosporum orbiculare. Semin. Dermatol. 2:26-29.

26a.Cookson, W. O. 1999. The genetics of atopic dermatitis: strategies, candidate genes, and genome screens. J. Am. Acad. Dermatol. 45(1 Suppl.):S7S9.

27. Cox, H., W. O. C. M. Cookson, and J. Harper. 2000. Genetics of atopic dermatitis, p. 169-177. In J. Harper, A. Oranje, and N. Prose (ed.), Pediatric dermatology. Blackwell Science, Oxford, United Kingdom.

28. Devos, S. A., and P. G. M. van der Valk. 2000. The relevance of skin prick tests for Pityrosporum ovale in patients with head and neck dermatitis. Allergy 55:1056-1058.

29. Doekes, G., and A. G. van Leperen-van Dijk. 1991. Allergens of Pityrosporum ovale and Candida albicans. I. Cross-reactivity of IgE-binding components. Allergy 48:394-400.

30. Doekes, G. M. J., M. J. H. Kaal and A. G. van Leperen-van Dijk. 1993. Allergens of Pityrosporum ovale and Candida albicans. II. Physicochemical characterization. Allergy 48:401-408.

31. Eichstedt, E. 1846. Pilzbildung in der Pityriasis versicolor. Frorip Neue Not Geb. Naturkd. Heilkd. 39:270.

32. Erchiga, V. C., A. O. Martos, A. V. Casano, A. C. Erchiga, and F. S. Fajardo. 2000. Malassezia globosa as the causative agent of pityriasis versicolor. Br. J. Dermatol. 143:799-803.

33. Faergemann, J., and T. Fredriksson. 1980. Age incidence of Pityrosporum orbiculare on human skin. Acta Dermato-Venereol. 60:531-533.
34. Faergemann, J., and T. Fredriksson. 1981. Experimental infections in rabbits and humans with Pityrosporum orbiculare and $P$. ovale. J. Investig. Dermatol. 77:314-318.

35. Faergemann, J., R. Aly, and H. I. Maibach. 1983. Quantitative variations in distribution of Pityrosporum orbiculare on clinically normal skin. Acta Dermato-Venereol. 63:346-348.

36. Faergemann, J. 1985. Lipophilic yeasts in skin disease. Semin. Dermatol. 4:173-184.

37. Faergemann, J. 1987. The use of contact plates for quantitative culture of Pityrosporum orbiculare. Mykosen 30:298-304.

38. Faergemann, J. 1995. Pityriasis versicolor (Tinea versicolor), vol. 3, p. 1-11. In D. S. Demis (ed.), Clinical dermatology, 27th ed. Lippincott-Raven, Philadelphia, Pa.

39. Faergemann, J. 1997. Pityrosporum yeasts—what's new? Mykoses 40(Suppl. 1):29-32.

40. Faergemann, J. 1999. The role of infections and colonization with microorganisms in atopic dermatitis, p. 98-110. In A. Waersted, B. Beerman, P. O. Roksvag, and K. Strandberg (ed.), Treatment of atopic dermatitis (second workshop). The Norwegian Medicines Control Authority and The Swedish Medical Products Agency, Oslo, Norway.

41. Faergemann, J. 1999. Pityrosporum species as a cause of allergy and infection. Allergy 54:413-419.

42. Faergemann, J. 2000. Management of seborrheic dermatitis and pityriasis versicolor. Am. J. Clin. Dermatol. 1:75-80.

43. Faergemann, J., I. M. Bergbrant, M. Dohsé, A. Scott, and G. Westgate. 2001. Seborrhoeic dermatitis and Pityrosporum (Malassezia) folliculitischaracterization of inflammatory cells and mediators in the skin by immunohistochemistry. Br. J. Dermatol. 144:549-556.

44. Goh, C. L., J. S. Wong, and Y. C. Giam. 1997. Skin colonization of Staphylococcus aureus in atopic dermatitis patients seen at the National Skin Centre, Singapore. Int. J. Dermatol. 36:653-657.

45. Gordon, M. A. 1951. Lipophilic yeast like organisms associated with tinea versicolor. J. Investig. Dermatol. 17:267-272.

46. Gordon, M. A. 1951. The lipophilic mycoflora of the skin. Mycologia 43: $524-534$.

47. Gruby, M. 1842. Recherches anatomiques sur une plant cryptogame qui constitue le vrai muguet des enfants. C. R. Acad. Sci. (Paris) 14:634-636.

48. Gueho, E., G. Midgley, and J. Guillot. 1996. The genus Malassezia with description of four new species. Antonie Leeuwenhoek 69:337-355.

49. Guillot, J., E. Gueho, M. Lesourd, G. Midgley, G. Chévrier, and B. Dupont. 1996. Identification of Malassezia species-a practical approach. J. Mycol. Med. 6:103-110.

50. Gupta, A. K., Y. Kohli, A. Li, J. Faergemann, and R. C. Summerbell. 2000. In vitro susceptibility of the seven Malassezia species to ketoconazole, voriconazole, itraconazole and terbinafine. Br. J. Dermatol. 142:758-765.

51. Gupta, A. K., Y. Kohu, J. Faergemann, and R. C. Summerbell. 2001. Epidemiology of Malassezia yeasts associated with pityriasis versicolor in Ontario, Canada. Med. Mycol. 39:199-206.

52. Gupta, A. K., Y. Kohli, R. C. Summerbell, and J. Faergemann. 2001. Quantitative culture of Malassezia species from different body sites of individuals with or without dermatoses. Med. Mycol. 39:243-251.

53. Hanifen, J., and G. Rajka. 1980. Diagnostic features of atopic dermatitis. Acta Dermato-Venereol. 92(Suppl.):44-47.

54. Hanifen, J., and J.-H. Saurat. 2001. Understanding atopic dermatitis: pathophysiology and etiology. J. Am. Acad. Dermatol. 45(Suppl. 1):1-68.

55. Hanifen, J. M., M. R. Ling, R. Langley, D. Breneman, and E. Rafal. 2001. Tacrolimus ointment for the treatment of atopic dermatitis in adult patients. Part I. efficacy. J. Am. Acad. Dermatol. 44(Suppl. 1):28-38.

56. Hanifen, J. M., M. Thurston, M. Omoto, R. Cherill, S. J. Tofte, and M. Graeber 2001. The eczema area and severity index (EASI): assessment of reliability in atopic dermatitis. Exp. Dermatol. 10:11-18.

57. Hay, R. J., and G. Shennan. 1982. Chronic dermatophyte infections. II. Antibody and cell-mediated immune responses. Br. J. Dermatol. 106:191195.

58. Hay, R. J. and M. Moore. 1998. Mycology, p. 1277-1376. In R. H. Champion, J. L. Burton, D. A. Burns, and S. M. Breathnach (ed.), Rook/Wilkinson/Ebling textbook of dermatology, 6th ed., vol. 2. Blackwell Science, Oxford, United Kingdom.

59. Herz, U., R. Bunikowski, M. Mielke, and H. Renz. 1999. Contribution of bacterial superantigens to stopic dermatitis. Int. Arch. Allergy Immunol. 118:240-241.

60. Hoeger, P. H., W. Lenz, A. Boutonnier, and J. M. Fournier. 1992. Staphylococcal skin colonization in children with atopic dermatitis. Prevalence, persistence and transmission of toxigenic and nontoxigenic strains. J. Infect. Dis. 165:1064-1068.

61. Hoog, G. S., J. Guarro, J. Gené, and M. J. Figueras (ed.). 2000. Atlas of clinical fungi, 2nd ed., p. 144-155. Centraalbureau voor Schimmelcultures/ Universitat Rovira i Virgili, Reus, Spain.

62. Huang, X., S. G. O. Johansson, A. Zargari, and S. L. Nordvall. 1995 Allergen cross-reactivity between Pityrosporum orbiculare and Candida albicans. Allergy 50:648-656. 
63. Hughes, H., and E. Hamilton. 1958. Pityrosporum ovale as a cause of allergy to human scurf. Br. Med. J. Aug:542-543.

64. Ishigura, A., M. Homma, S. Torii, and K. Tanaka. 1992. Identification of Candida albicans antigens reactive with immunoglobulin E antibody of human sera. Infect. Immun. 60:1550-1557.

65. Jekler, J., I. M. Bergbrant, J. Faergemann, and O. Larko. 1992. The in vitro effect of UVB radiation on skin bacteria in patients with atopic dermatitis. Acta Dermato-Venereol. 72:33-36.

66. Jensen-Jarolim, E., L. K. Poulsen, H. With, M. Kieffer, V. Ottevanger, and P. S. Skov. 1992. Atopic dermatitis of the face, scalp and neck: type I reaction to the yeast Pityrosporum ovale? J. Allergy Clin. Immunol. 89:44-50.

66a.Johansson, C., M. H. Sandstrom, J. Bartosik, T. Sarnhult, J. Christiansen, A. Zargari, O. Back, C. F. Wahlgren, J. Faergemann, A. Scheynius, and M. Tengvall Linder. Atopy patch test reactions to Malassezia allergens differentiate subgroups of atopic dermatitis patients. Br. J. Dermatol., in press.

67. Jones, H. E., J. H. Reinhardt, and M. G. Rinaldi. 1973. A clinical, mycological, and immunological survey for dermatophytosis. Arch. Dermatol. 108:61-65.

68. Jones, H. E., J. H. Reinhardt and M. G. Rinaldi. 1974. Immunologic susceptibility to chronic dermatophytosis. Arch. Dermatol. 110:213-220.

69. Johansson, S., and K. Karlstrom. 1991. IgE-binding components in Pityrosporum orbiculare identified by an immunoblotting technique. Acta Dermato-Venereol. 71:11-16.

70. Johansson, C., M. Jeddi-Tehrani, J. Grunewald, M. Tengvall-Linder, A. Bengtsson, G. Hallden, and A. Scheynius. 1999. Peripheral blood T-cell receptor $\beta$-chain $\mathrm{V}$-repertoire in atopic dermatitis patients after in vitro exposure to Pityrosporum orbiculare extract. Scand. J. Immunol. 49:293-301.

71. Kane, J., R. Summerbell, L. Sigler, S. Krajden, and G. Land. 1997. Laboratory handbook of dermatophytes. Star Publishing Co., Belmont, Calif.

72. Kunz, B., and J. Ring. 2000. Clinical features and diagnostic criteria of atopic dermatitis. p. 199-214. In J. Harper, A. Oranje, and N. Prose (ed.), Textbook of pediatric dermatology. Blackwell Science, Oxford, United Kingdom.

73. Kawamura, M. S., S. Aiba, and H. Tagami. 1998. The importance of CD54 and CD86 costimulation in T cells stimulated with Candida albicans and Dermatophagoides farinae antigens in patients with atopic dermatitis. Arch. Dermatol. Res. 290:603-609.

74. Kieffer, M., I. M. Bergbrant, J. Faergemann, G. B. Jemec, V. Ottevanger, P. S. Skov, and E. Svejgaard. 1990. Immune reactions to Pityrosporum ovale in adult patients with atopic dermatitis and seborrhoeic dermatitis. J. Am. Acad. Dermatol. 22:739-742.

75. Kim, T. Y., I. G. Jang, Y. M. Park, H. O. Kim, and C. W. Kim. 1999. Head and neck dermatitis: the role of Malassezia furfur, topical steroid use and environmental factors in its causation. Exp. Dermatol. 24:226-231.

76. Kim, S. C., and H. U. Kim. 2000. The distribution of Malassezia species on the normal human skin according to body region. Kor. J. Med. Mycol. 5:120-128.

77. Kimura, M., S. Tsuruta, and T. Yoshida. 1999. Differences in cytokine production by peripheral blood mononuclear cells (PBMC) between patients with atopic dermatitis and bronchial asthma. Clin. Exp. Immunol 118:192-196.

78. Kimura, K., S. Tsuruta, and T. Yoshida. 2000 . IFN- $\gamma$ plays a dominant role in upregulation of Candida-specific $\operatorname{IgE}$ synthesis in patients with atopic dermatitis. Int. Arch. Allergy Immunol. 122:195-199.

79. Klein, P. A., S. Brook, R. A. F. Clark, and N. H. Nicol. 1999. Acute infection with Trichophyton rubrum associated with flares of atopic dermatitis. Cutis 63:171-172.

80. Klubal, R., B. Osterhoff, B. Wang, J.-P. Kinet, D. Maurer, and G. Stingl. 1997. The high-affinity receptor for IgE is the predominant IgE-binding structure in lesional skin of atopic dermatitis patients. J. Investig. Dermatol. 108:336-342

81. Kortekangas-Savolainen, O. K. Kalimo, K. Lammintausta, and J. Savolainen. 1993. IgE-binding components of baker's yeast (Saccharomyces cerevisiae) recognized by immunoblotting analysis. Simultaneous IgE binding to mannan and 46-48 kD allergens of Saccharomyces cerevisiae and Candida albicans. Clin. Exp. Allergy 23:179-184.

82. Koyama, T., T. Kanbe, A. Ishiguro, A. Kikuchi, and Y. Tomita. 2000. Isolation and characterization of a major antigenic component of Malassezia globosa to $\operatorname{IgE}$ antibodies in sera of patients with atopic dermatitis. Microbiol. Immunol. 44:373-379.

83. Kroger, S., K. Neuber, E. Gruseck, J. Ring, and D. Abeck. 1995. Pityrosporum ovale extracts increase interleukin-4, interleukin-10 and IgE synthesis in patients with atopic dermatitis. Acta Dermato-Venereol. 75:357-360.

84. Lacour, M., and C. Hauser. 1993. The role of microorganisms in atopic dermatitis. Clin. Rev. Allergy 11:491-522.

85. Langenbeck, B. 1939. Auffingung von Pilzen aus der Schleimhaut der Speiseröhre einer Typhus-Leiche. Neue Not. Geb. Naturkd. Heilkd. 12: 145-147.

86. Larko, O. 1999. Phototherapy of atopic dermatitis, traditional therapies, p. 147-160. In A. Waersted, B. Beaman, P. O. Roksvag, and K. Strandberg (ed.), Treatment of atopic dermatitis (second workshop). The Norwegian
Medicines Control Authority and The Swedish Medical Products Agency, Oslo, Norway.

87. Leeming, J. P., and F. H. Notman. 1987. Improved methods for isolation and enumeration of Malassezia furfur from human skin. J. Clin. Microbiol. 25:2017-2019.

88. Leeming, J. P., F. H. Notman, and K. T. Holland. 1989. The distribution and ecology of Malassezia furfur and cutaneous bacteria in human skin. J. Appl. Bacteriol. 67:47-52.

89. Leung, D. Y. M., J. B. Travers, and D. A. Norris. 1995. The role of superantigens in skin disease. J. Investig. Dermatol. 105:37-42.

90. Leung, D. Y. M., P. Hauk, I. Strickland, J. B. Travers, and D. A. Norris 1998. The role of superantigen in human diseases: therapeutic implications for the treatment of skin diseases. Br. J. Dermatol. 139:17-29.

91. Leung, D. Y. M. 1999. Therapeutic perspectives in atopic dermatitis. Allergy 54(Suppl. 58):39-42.

92. Leung, D. Y. L., and N. S. Soter. 2001. Cellular and immunologic mechanisms in atopic dermatitis. J. Am. Acad. Dermatol. 44:S1-S12.

93. Lever, R., K. Hadley, D. Downey and R. Mackie. 1988. Staphylococca colonization in atopic dermatitis and the effect of topical mupirocin therapy. Br. J. Dermatol. 119:189-198.

94. Lever, R. 1996. Infection in atopic dermatitis. Dermatol. Ther. 1:32-37.

95. Leyden, J. J., R. R. Marples, and A. M. Kligman. 1974. Staphylococcus aureus in lesions of atopic dermatitis. Br. J. Dermatol. 80:525-530.

96. Lindborb, M., C. G. M. Magnusson, A. Zagari, M. Schmidt, A. Scheynius, R. Crameri, and P. Whitley. 1999. Selective cloning of allergens from the skin colonizing yeast Malassezia furfur by phage surface display technology. J. Investig. Dermatol. 113:156-161.

97. Lindgren, L., C. F. Wahlgren, S. G. O. Johansson, I. Wiklund, and S. L. Nordvall. 1995. Occurence and clinical features of sensitization to Pityrosporum orbiculare and other allergens in children with atopic dermatits. Acta Dermato-Venereol. 75:300-304.

98. Lintu, P., J. Savolainen, and K- Kalimo. 1997. IgE antibodies tp protein and mannan antigens of Pityrosporum ovale in atopic dermatitis patients. Clin. Exp. Allergy 27:87-95.

99. Lintu, P. J. Savolainen, K. Kalimo, and E. O. Terho. 1998. Stability of Pityrosporum ovale allergens during storage. Clin. Exp. Allergy 28:486-490.

100. Lintu, P., J. Savolainen, K. Kalimo, O. Kortekangas-Savolainen, M Nermes, and E. O. Terho. 1999. Cross-reacting IgE and IgG antibodies to Pityrosporum ovale mannan and other yeasts in atopic dermatitis. Allergy 54:1067-1073

101. Lintu, P., J. Savolainen, O- Kortekangas-Savolainen, and K. Kalimo. 2001. Systemic ketoconazole is an effective treatment of atopic dermatitis with IgE-mediated hypersensitivity to yeasts. Allergy 56:512-517.

102. Matsumura, N., S. Aiba, M. Tanaka, H. Aoyama, N. Tabata, G. Tamura and H. Tagami. 1997. Comparison of immune reactivity profiles against various environmental allergens between adult patients with atopic dermatitis and patients with allergic respiratory diseases. Acta Dermato-Venereol. 77:388-391.

103. Mayser, P., and A. Gross. 2000. IgE antibodies to Malassezia furfur, $M$. sympodialis and Pityrosporum orbiculare in patients with atopic dermatitis, seborrheic eczema or pityriasis versicolor, and identification of respective allergens. Acta Dermato-Venereol. 80:357-361.

104. McGregor, J. M., A. Hamilton, and R. J. Hay. 1992. Possible mechanism of immune modulation in chronic dermatophytoses-an in vitro study. Br. J. Dermatol. 128:233-238.

105. Mittag, H. 1995. Fine structural investigations of Malassezia furfur. II. The envelope of the yeast cells. Mycoses 38:13-21.

106. Morita, E., M. Hide, Y. Yoneya, M. Kannbe, A. Tanaka, and S. Yamamoto 1999. An assessment of the role of Candida albicans antigen in atopic dermatitis. J. Dermatol. 26:282-287.

107. Nakabayshi, A., Y. Sei, and J Guillot. 2000. Identification of Malassezia species isolated from patients with seborrhoeic dermatitis, atopic dermatitis, pityriasis versicolor and normal subjects. Med. Mycol. 38:337-341.

108. Nermes, M., K. Falth-Magnusson, J. Savolainen, M. Viander, and B Bjorksten. 1996. A comparison of the development of antibody responses to the polysaccharide antigen (Candida albicans mannan) in atopic and healthy infants and children. Clin. Exp. Allergy 26:164-170.

109. Nissen, D., L. J. Petersen, R. Esch, E. Svejgaard, P. S. Skov, L. K. Poulsen, and H. Nolte. 1998. IgE-sensitization to cellular and culture filtrates of fungal extracts in patients with atopic dermatitis. Ann. Allergy Asth. Immunol. 81:247-255.

110. Noble, W. C. 1996. The role of staphylococci in dermatology. J. Eur. Acad. Dermatol. Venereol. 7(Suppl.):12-14.

111. Odds, F. C. (ed.). 1988. Candida and candidosis, 2nd ed. The W. B. Saunders Co., Baltimore, Md.

112. Odds, F. C. 1994. Pathogenesis of Candida infections. J. Am. Acad. Dermatol. 31:S2-S5.

113. Okudaira, H, O. Hongo, T. Ogita, M. Haida, N. Yamauchi, and T. Miyamoto. 1983. Serum IgE and IgE antibody levels in patients with bronchial asthma, atopic dermatitis, eosinophilic granulomas of the soft tissue (Kimura's disease) and other diseases. Ann. Allergy 50:51-54.

114. Onishi, Y, K., M. Kuroda, H. Yasueda, A. Saito, E. Sono-Koyama, S. 
Tunasawa, T. Hashida-Okada, T. Yagihara, K. Uchida, H. Yamaguchi, K. Akiyama, I. Kato, and K. Takesako. 1999. Two-dimensional electrophoresis of Malassezia allergens for atopic dermatitis and isolation of Mal f 4 homologs with mitochondrial malate dehydrogenase. Eur. J. Biochem. 261: 148-154.

115. Platts-Mills, T. A. E., G. P. Fiocco, and S. Pollart. 1986. Trichophyton allergy in a 24-year-old man with intrinsic asthma. Ann. Allergy 56:454-455.

116. Rajka, G. (ed.). 1975. Atopic dermatitis. The W. B. Saunders Co., Baltimore, Md

117. Rajka, G., and C. Barlinn. 1979. On the significance of the trichophytin reactivity in atopic dermatitis. Acta Dermato-Venereol. 59:45-47.

118. Ramsay, C. A., J. M. Savoie, M. Gilbert, M. Gideon, and P. Kidson. 1996 The treatment of atopic dermatitis with topiocal fusidic acid and hydrocortisone acetate. J. Eur. Acad. Dermatol. Venereol. 7(Suppl.):15-22.

119. Rasool, O., A. Zargari, J. Almqvist, H. Eshaghi, P. Whitley, and A. Scheynius. 2000. Cloning, characterization and expression of complete coding sequences of three IgE binding Malassezia furfur allergens, Mal f 7, Mal f 8 and $\mathrm{Mal} f$ 9. Eur. J. Biochem. 267:4355-4361.

120. Redline, R. W., and B. B. Dahms. 1981, Malassezia pulmonary vasculitis in an infant on long-term intralipid therapy. N. Engl. J. Med. 395:1395-1398.

121. Rivolta, S. 1874. Parassiti vegetali, di Giulo Speiranai. F. Giglo, Turin, Italy.

122. Roberts, S. O. B. 1969. Pityrosporum orbiculare: incidence and distribution on clinically normal skin. Br. J. Dermatol. 81:264-269.

123. Roberts, S. O. B. 1969. Pityriasis versicolor: a clinical and mycological investigation. Br. J. Dermatol. 81:315-326.

124. Robin, C. P. 1853 . Historie naturelle des végétaux. Parasites qui croissent sur l'homme et sur les animaux vivants. Ballière, Paris, France.

125. Rokugo, M., H. Tagami, Y. Usuba, and Y. Tomota. 1990. Contact sensitivity to Pityrosporum ovale in patients with atopic dermatitis. Arch. Dermatol. 126:627-632.

126. Romani, L., F. Bistoni, and P. Pucetti. 1997. Initiation of T-helper cell immunity to Candida albicans by IL-12: the role of neutrophils. Chem. Immunol. 68:110-135.

127. Sabouraud, R. 1904. Malasies du cuir chevulu. Masson et Cie, Paris, France.

128. Salkin, I. F., and M. A. Gordon. 1977. Polymorphism of Malassezia furfur. Can. J. Microbiol. 23:471-475.

129. Samaranayake, Y. H., and L. P. Samaranayake. 2001. Experimental oral candidiasis in animal models. Clin. Microbiol. Rev. 14:398-429.

130. Sampson, H. A. 1989. Food allergy. J. Allergy Clin. Immunol. 84:1062-1067.

131. Savolainen, J., and A. Broberg. 1992. Cross-reacting IgE antibodies to Pityrosporum ovale and Candida albicans in atopic children. Clin. Exp. Allergy 22:469-474.

132. Savolainen, J. K. Lammintausta, K. Kalimo, and M. Viander. 1993. Candida albicans and atopic dermatitis. Clin. Exp. Allergy 23:332-339.

133. Savolainen, J., O. Kortekangas-Savolainen, M. Nermes, M. Viander, A. Koivikko, K. Kalimo, and E. O. Terho. 1998. IgE, IgA, and IgG responses to common yeasts in atopic patients. Allergy 53:506-512.

134. Savolainen, J., J. Kosonen, P. Lintu, M. Viander, J. Pene, K. Kalimo, E. O. Terho, and J. Bousquet. 1999. Candida albicans mannan- and proteininduced humoral, cellular and cytokine responses in atopic dermatitis patients. Clin. Exp. Allergy 29:824-831

135. Savolainen, J., P. Lintu, J. Kosonen, O. Kortekangas-Savolainen, M. Viander, J. Pene, K. Kalimo, E. O. Terho, and J. Bousquet. 2001. Pityrosporum and Candida specific and non-specific humoral, cellular and cytokine responses in atopic dermatitis patients. Clin. Exp. Allergy 31:125-134.

136. Scalabrin, D. M. F., S. Bavbek, S. Matthew, B. S. Perzanowski, B. B. Wilson, T. A. E. Platts-Mills, and L. M. Wheatley. 1999. Use of specific IgE in assessing the relevance of fungal and dust mote allergens to atopic dermatitis: a comparison with asthmatic and non asthmatic control subjects. J. Allergy Clin. Immunol. 104:1273-1279.

137. Schmidt, M., A. Zargari, P. Holt, L. Lindbom, U. Hellman, P. Whitley, I. van der Ploeg, B. Harfast, and A. Scheynius. 1997. The complete cDNA sequence and expression of the first major allergenic protein of Malassezia furfur, Mal f 1. Eur. J. Biochem. 246:181-185.

138. Reference deleted.

139. Skov, L., and O. Baadsgaard. 1996. The potential role of Staphyloccus aureus superantigens in atopic dermatitis. J. Eur. Acad. Dermatol. Venereol. 7(Suppl.):8-11.

140. Sloof, W. C. 1971. Genus Pityrosporum, p. 1167-1186. In Lodder (ed.), The yeasts, 2nd ed. North-Holland Publishing, Amsterdam, The Netherlands.

141. Stalder, J. F., D. J. Atherton, T. Bieber, et al. 1993. Consensus Report of the European Task Force on Atopic Dermatitis. Severity scoring of atopic dermatitis: the SCORAD index. Dermatology 186:23-31.

142. Strickland, I., P. J. Hauk, A. E. Trumble, L. J. Picker, and D. Y. M. Leung. 1999. Evidence for superantigen involvement in skin homing of T cells in atopic dermatitis. J. Investig. Dermatol. 112:249-253.

143. Svejgaard, E., J. Faergemann, G. Jemic, M. Kieffer, and V. Ottevanger. 1989. Recent investigations on the relationship between fungal skin diseases and atopic dermatitis. Acta Dermato-Venereol. 144(Suppl.):140-142.
144. Svejgaard, E. 1990 . The role of microorganisms in atopic dermatitis. Semin. Dermatol. 9:255-261.

145. Svensson, A. 1999. Atopic dermatitis epidemiology, p. 37-50. In A. Waersted, B. Beeman, P. O. Roksvag, and K. Strandberg (ed.), Treatment of atopic dermatitis (second workshop). The Norweglan Medicines Control Authority and the Swedish Medical Products Agency, Oslo, Norway.

146. Sorensen, L. H. 1999. Atopic dermatitis-barrier function and skin care products (SCPs), p. 126-146. In A. Waersted, B. Beeman, P. O. Roksvag, and K. Strandberg (ed.), Treatment of atopic dermatitis (second workshop). The Norwegian Medicines Control Authority and the Swedish Medical Products Agency, Oslo, Norway.

147. Tanaka, M., S. Aiba, N. Matsumura, H. Aoyama, N. Tabata, Y. Sekita and H. Tagami. 1994. IgE-mediated hypersensitivity and contact sensitivity to multiple environmental allergens in atopic dermatitis. Arch. Dermatol. 130:1393-1401.

148. Tanaka, M., S. Aiba, K. Takahashi, and H. Tagami. 1996. Reduced proliferative responses of peripheral blood mononuclear cells specifically to Candida albicans antigen in patients with atopic dermatitis-comparison with their normal reactivity to bacterial superantigens. Arch. Dermatol. Res. 288:495-499.

149. Tengvall-Linder, M., S. Johansson, A. Zargari, A. Bengtsson, I. van der Ploeg, B. Harfast, and A. Scheynius. 1996. Detection of Pityrosporum orbiculare reactive $\mathrm{T}$ cells from skin and blood in atopic dermatitis and characterization of their cytokine profiles. Clin. Exp. Allergy 26:1286-1297.

150. Tengvall-Linder, M., C. Johansson, A. Bengtsson, L. Holm, B. Harfast and A. Scheynius. 1998. Pityrosporum orbiculare-reactive T-cell lines in atopic dermatitis patients and healthy controls. Scand. J. Immunol. 47:152-158.

151. Tengvall-Linder, M., C. Johansson, A. Scheynius, and C. F. Wahlgren. 2000. Positive patch test reactions to Pityrosporim orbiculare in atopic dermatitis patients. Clin. Exp. Allergy 30:122-131.

152. Thestrup-Pedersen, K. 1996. The incidence and pathophysiology of atopic dermatitis. J. Eur. Acad. Dermatol. Venereol. 7(Suppl.):3-7.

153. Unna, P. G. 1891. Notice. Monatschr. Prakt. Dermatol. 13:225-237.

153a.von Sehlen. 1880. Ueber die Zuchtung von Pityriasis versicolor. Tegebl. Versamml. Dtsch. Naturforsch. Aerzth. 600.

154. Waersted, A., and N. Hjorth. 1985. Pityrosporum orbiculare-a pathogenic factor in atopic dermatitis of the face, scalp and neck? Acta DermatoVenereol. 114(Suppl.):146-148.

155. Ward, G. W., G. Karlsson, and G. Rose. 1989. Trichophyton asthma: sensitization of bronchi and upper airways to dermatophyte antigen. Lancet i:859-862.

156. Watanabe, S., R. Kano, H. Sato, Y. Nakamura and Y. Hasegawa. 2001. The effects of Malassezia yeasts on cytokine production by human keratinocytes. J. Investig. Dermatol. 116:769-773.

157. Wessels, M. W., G. Doekes, A. G. van Leperen-van Dijk, W. J. Koers, and E. Young. 1991. IgE antibodies to Pityrosporum ovale in atopic dermatitis. Br. J. Dermatol. 125:227-232

158. White, I., and I. Blatchford. 1983. The treatment of secondary bacterial infections in atopic eczema with miconazole plus hydrocortisone. $\mathrm{Br}$. J. Clin. Pract. June:215-216.

159. Williams, H. C., P. Burney, A. Pembroke, and R. Hay. 1994. The U. K. Working party's diagnostic criteria for atopis dermatitis. III. Independent hospital validation. Br. J. Dermatol. 131:406-416.

160. Williams, H. C. 2000. Epidemiology of atopic dermatitis. Clin. Dermatol. 25:522-529.

161. Williams, H. C., and B. Wüthrich. 2000. The natural history of atopic dermatitis, p. 41-59 In H. C. Williams (ed.), Atopic dermatitis. Cambridge University Press, Cambridge, United Kingdom.

162. Reference deleted.

163. Wilson, B. B., B. Deuell, and T. A. E. Platts Mills. 1993. Atopic dermatitis associated with dermatophyte infection and Trichophyton hypersensitivity. Cutis 51:191-192.

164. Wollenberg, A., S. Kraft, T. Oppel, and T. Bieber. 2000. Atopic dermatitis: pathogenetic mechanisms. Clin. Exp. Dermatol. 25:530-534.

165. Yasueda, H., T. Hashida-Okada, A. Saito, K. Uchida, M. Kuroda, Y. Onishi, K. Takahashi, H. Yamaguchi, K. Takasako, and K. Akiyama. 1998. Identification and cloning of two novel allergens from the lipophilic yeast, Malassezia furfur. Biochem. Biophys. Res. Commun. 248:240-244.

166. Zargari, A., B. Harfast, S. Johansson, S. G. O. Johansson and A. Scheynius. 1994. Identification of allergen components of the opportunistic yeast Pityrosporum orbiculare by monoclonal antibodies. Allergy 49:50-56.

167. Zargari, A., G. Doekes, A. G. van Leperen-vanDijk, E. Landberg, B. Harfast, and A. Scheynius. 1995. Influence of culture period on the allergenic composition of Pityrosporum orbiculare extracts. Clin. Exp. Allergy 25:1235-1245.

168. Zollner, T. M., T. A. Wichelhaus, A. Hartung, C. von Mallinckrodt, T. O. Wagner, V. Brade, and R. Kaufmann. 2000. Colonization with superantigen-producing Staphylococcus aureus is associated with increased severity of atipis dermatitis. Clin. Exp. Allergy 30:994-1000. 